\title{
RENATA ESCORCIO
}

Elaboração e análise de confiabilidade de escala de avaliação funcional da manobra de Gowers e da passagem de bipedestação para sedestação no solo para portadores de distrofia muscular de Duchenne (DMD)

Dissertação apresentada à Faculdade de Medicina da Universidade de São Paulo para obtenção do título de Mestre em Ciências

Área de concentração: Movimento, Postura e Ação Humana Orientadora: Profa. Dra. Fátima Aparecida Caromano

\section{São Paulo}




\section{RENATA ESCORCIO}

Elaboração e análise de confiabilidade de escala de avaliação funcional da manobra de Gowers e da passagem de bipedestação para sedestação no solo para portadores de distrofia muscular de Duchenne (DMD)

Dissertação apresentada à Faculdade de Medicina da Universidade de São Paulo para obtenção do título de Mestre em Ciências

Área de concentração: Movimento, Postura e Ação Humana

Orientadora: Profa. Dra. Fátima Aparecida Caromano

São Paulo 


\section{Dados Internacionais de Catalogação na Publicação (CIP)}

Preparada pela Biblioteca da

Faculdade de Medicina da Universidade de São Paulo

Creprodução autorizada pelo autor

\section{Escorcio, Renata}

Elaboração e análise de confiabilidade de escala de avaliação funcional da manobra de Gowers e da passagem de bipedestação para sedestação no solo para portadores de distrofia muscular de Duchenne (DMD) / Renata Escorcio. -- São Paulo, 2009.

Dissertação(mestrado)--Faculdade de Medicina da Universidade de São Paulo. Departamento de Fisioterapia, Fonoaudiologia e Terapia Ocupacional.

Área de concentração: Movimento, Postura e Ação Humana.

Orientadora: Fátima Aparecida Caromano.

Descritores: 1.Distrofia muscular de Duchenne 2.Avaliação 3.Exame físico 4.Doenças musculares 


\section{Dedicatória}

À DEUS,

Ao Mestre Jesus,

E a todas as crianças com miopatias

"Se não fosse por elas, este trabalho seria em vão" 


\section{Agradecimentos}

Os mais sinceros agradecimentos à professora fátima Aparecida Caromano, por me introduzir no caminho da Ciência e por fazer de cada encontro um aprendizado.

A toda minha familia...

Aus meus amores, Heloísa C. R. Escorcio e Victória L. Escorcio, que tanto me alegram a vida.

Aos meus pais Antonio Escorcio e Maria Isabel Escorcio, pelo amor acima de tudo, por apoiarem as minhas esculhas e sempre se orgulharem de cada conquista.

Ao Marcelo Alvarez, companheiro de todas as horas, pelo amor, cumpreensão, paciência e principalmente por me deixar amar.

As amigas Lilian Ap. Yoshimura Fernandes e Michele E. Hukuda, pela essencial contribuição no desenvolvimento deste trabalho.

A "tia" amiga Valéria R. B. Escurcio, pela disponibilidade e dedicação. 
Esta dissertação ou tese está de acordo com as seguintes normas, em vigor no momento desta publicação:

Referências: adaptado de International Committee of Medical Journals Editors (Vancouver)

Universidade de São Paulo. Faculdade de Medicina. Serviço de Biblioteca e Documentação. Guia de apresentação de dissertações, teses e monografias. Elaborado por Anneliese Carneiro da Cunha, Maria Julia de A. L. Freddi, Maria F. Crestana, Marinalva de Souza Aragão, Suely Campos Cardoso, Valéria Vilhena. 2a ed. São Paulo: Serviço de Biblioteca e Documentação; 2005.

Abreviaturas dos títulos dos periódicos de acordo com List of Journals Indexed in Index Medicus. 


\section{SUMÁRIO}

Lista de abreviaturas

Lista de tabelas

Lista de figuras

Resumo

Summary

1 INTRODUÇÃO

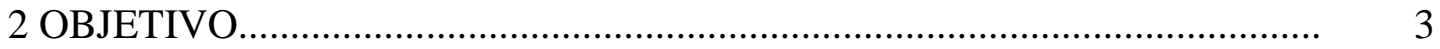

3 REVISÃO DA LITERATURA................................................................ 4

3.1 Distrofia muscular de Duchenne................................................................... 4

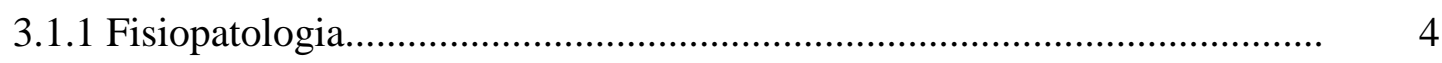

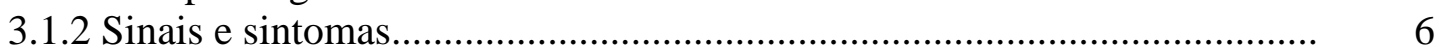

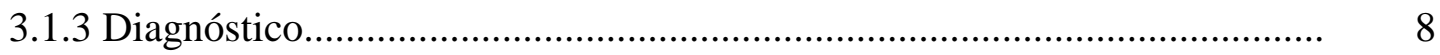

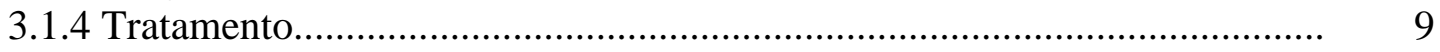

3.2 Avaliação funcional de pessoas com DMD................................................. 10

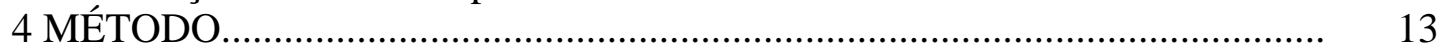

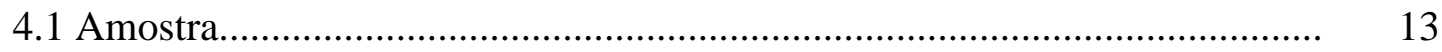

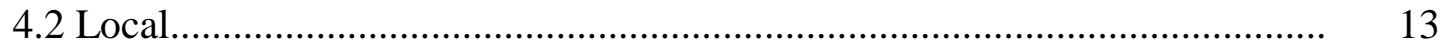

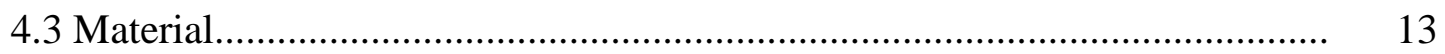

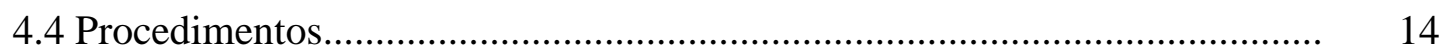

4.4.1 Construção da escala...................................................................... 14

4.4.1.1 Versão Inicial................................................................................ 14

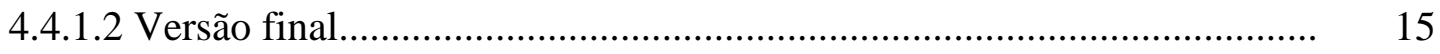

4.4.1.3 Análise de repetibilidade e reprodutibilidade...................................... 17

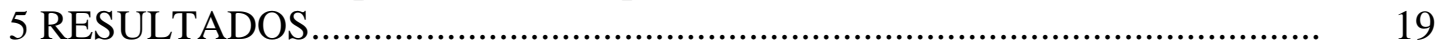

5.1 Confiabilidade intra e interexaminador................................................. 19

6 DISCUSSÃO

7 CONCLUSÃO

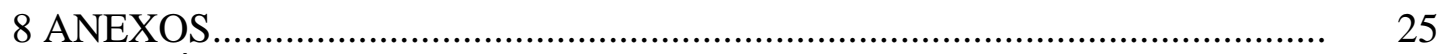

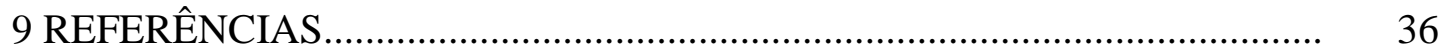




\section{LISTA DE ABREVIATURAS}

$\begin{array}{ll}\text { DMD } & \text { distrofia muscular de Duchenne } \\ \text { ICC } & \text { índice de correlação intra-classe } \\ \text { EK } & \text { Egen Klassifikation } \\ \text { AVD's } & \text { atividades de vida diária } \\ \text { MFM } & \text { medida da função motora } \\ \text { Fig. } & \text { figura } \\ \text { MMII } & \text { membros inferiores } \\ \text { CK } & \text { creatino-fosfokinase } \\ \text { EMG } & \text { eletromiografia } \\ \text { AVC } & \text { acidente vascular cerebral } \\ \text { et al } & \text { e outros } \\ \text { EAF-1 } & \text { escala de avaliação funcional do sentar e levantar da cadeira } \\ \text { EAF-3 } & \text { escala de avaliação funcional do subir e descer escadas } \\ \text { EAF-4 } & \text { escala de avaliação funcional de marcha } \\ \text { DNA } & \end{array}$




\section{LISTA DE FIGURAS}

Figura 1 - Corte histológico de tecido muscular de paciente com DMD. Observa-se variação no tamanho das fibras, necrose e proliferação de tecido conjuntivo.........................................................6

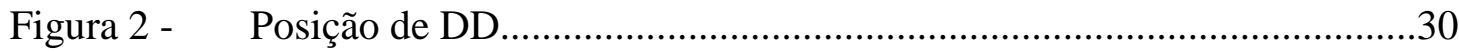

Figura 3 - $\quad$ Passagem de DD para flexão de tronco...................................................30

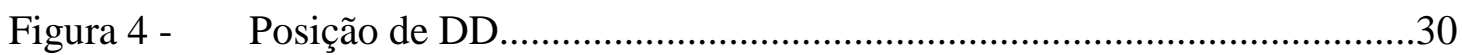

Figura 5 - $\quad$ De DD para flexão de tronco. Observe que não realiza DL.....................30

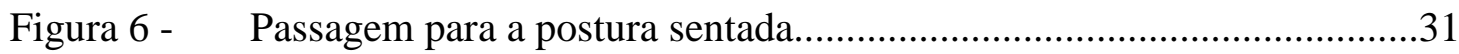

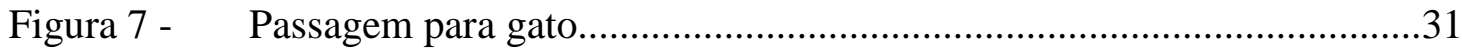

Figura 8 - Ajoelhado com apoio externo...............................................................

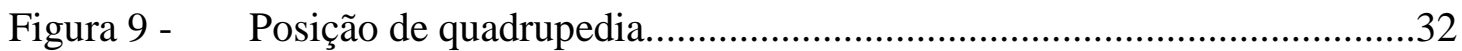

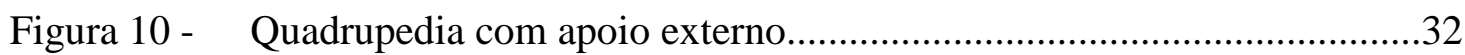

Figura 11 - De quadrupedia para bipedestação escalando joelhos ............................32

Figura 12 - De quadrupedia para bipedestação escalando joelho e apoio externo.

Figura 13 - Flexão de tronco com deslocamento do peso para frente com apoio no solo.............................................................................. 34

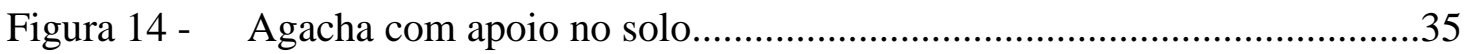

Figura 15 - Senta lateralizado e se estabiliza com apoio de MS...............................35 


\section{LISTA DE TABELAS}

Tabela 1 - EAF2 - DMD: Levantar do solo........................................................16

Tabela 2 - EAF2 - DMD - Sentar no solo........................................................ 17

Tabela 3 - Análise de repetibilidade (intra-examinador) e reprodutibilidade (interexaminador) das fases do sentar e levantar em portadores de distrofia muscular de

Duchenne. 


\section{Resumo}

Objetivo: Construir Escala de Avaliação Funcional do Sentar e Levantar do Solo para Portadores de DMD (EAF-2) e testar sua confiabilidade intra e interexaminadores. Método: A construção da escala ocorreu em etapas: 1. Análise do movimento de sentar e levantar do solo em crianças saudáveis. 2. Análise do movimento de sentar e levantar do solo em crianças com DMD. 3. Elaboração da primeira versão da escala e do manual de instrução. 4. Avaliação por peritos e reajustes gerando a versão final. 5. Análise de confiabilidade inter e intraexaminador e correlação com a Escala de Vignos, idade e tempo de execução da atividade. Resultados: A escala abrange três fases para o sentar e cinco para o levantar, cada fase contendo itens que devem ser avaliados e pontuados. O escore pode variar de 0 a 10 para o sentar e de 0 a 15 para o levantar. Foi demonstrado muito boa repetibilidade da medida do sentar e levantar $($ ICC $=0,89$ e 084, respectivamente) e excelente reprodutibilidade $(\mathrm{ICC}=0,93$ e 0,92 , respectivamente). $\mathrm{O}$ Coeficiente Kappa para as 8 fases na análise interexaminadores variou de 0,77 a 1,00 (confiabilidade excelente para 5 fases e substancial para 3 fases), e na análise intra-examinador variou de 0,80 a 1,00 (confiabilidade excelente para 6 fases e substancial para 2 fases). Encontrou-se boa correlação entre as variáveis idade x Escala de Vignos $(r=0,58)$ e levantar x Escala de Vignos $(r=0,56)$, enquanto que nas variáveis restantes a correlação foi baixa.Conclusão: A EAF-2 é um instrumento de avaliação confiável que permite avaliar a atividade de sentar e levantar em portadores de DMD de forma detalhada e operacionalizada.

Descritores: Distrofia muscular de Duchenne, Avaliação, Exame físico, Doenças musculares. 


\section{Summary}

Objective: Construct the Scale of Functional Evaluation of Sit-and-Stand from the Ground for Patients with DMD (EAF-2) and to test its reliability intra and interexaminer. Method: The construction of the scale occurred in stages: 1. Analysis of the movement to sit and stand from the ground in healthy children. 2. Analysis of the movement to sit and stand from the ground in children with DMD. 3. Elaboration of the first version of the scale and the manual of instruction. 4. Evaluation by experts and readjustments generating the final version. 5. Analysis of Reliability inter and intra-examiner and correlation with the Vignos Scale, age and time length for the execution of the activity. Results: The scale comprehends three phases for the sitting and five for the standing, each phase with items that must be evaluated and scored. The score may vary from 0 to 10 for the sitting and from 0 to 15 for the standing. A very good repeatability of the measure of sitting as well as of standing was demonstrated (ICC $=0,89$ and 084 , respectively) and excellent reproducibility (ICC $=0,93$ and 0,92 , respectively). The Kappa Coefficient for the 8 phases in the interexaminer analysis varied from 0,77 to 1,00

(excellent reliability for 5 phases and substantial for 3 phases),

and in the intra-examiner analysis varied from 0,80 to 1,00 (excellent reliability for 6 phases and substantial for 2 phases). Good correlation was found between the variable age $x$ Vignos Scale $(r=0,58)$ and to stand $x$ Vignos Scale $(r=0,56)$, whereas in the remaining variable the correlation was low. Conclusion: The EAF-2 is a trustful instrument of evaluation that allows to evaluate the activity of sitting and standing in people with DMD in a detailed and operationalized way.

Descriptors: Muscular dystrophy Duchenne, Evaluation, Physical Examination, Muscular Diseases. 


\section{INTRODUÇÃO}

A distrofia muscular de Duchenne é uma doença muscular progressiva e degenerativa $^{1-3}$, ligada ao cromossomo $\mathrm{X}$, caracterizada pela deficiência da proteína distrofina, resultando em necrose muscular ${ }^{4}$. Os primeiros sintomas aparecem precocemente na infância e comprometem primeiramente a musculatura proximal ${ }^{5,6}$. Sua incidência é de cerca de 1 para 3500 meninos nascidos vivos ${ }^{2,7}$.

Não existe cura até o momento e a intervenção fisioterapêutica, associada com tratamento medicamentoso, tem se mostrado eficiente em retardar o aparecimento de sinais e sintomas, melhorando a qualidade de vida e funcional destes pacientes ${ }^{8}$.

Para avaliação do déficit motor, a medida de força muscular por meio de testes musculares é o exame mais freqüentemente utilizado para acompanhar a evolução desta população, embora não reflita suas habilidades funcionais. $\mathrm{O}$ desempenho funcional depende da heterogeneidade do déficit, da compensação muscular e da limitação articular? .

Algumas escalas que avaliam função motora são validadas para DMD, como por exemplo, a escala funcional EK ( Egen Klassifikation) e o Índice de Barthel, que visam quantificar o grau de acometimento funcional para AVD's em cadeirantes ${ }^{10,11}$. $\mathrm{O}$ escore da escala funcional EK varia de 0 a 30 , e quanto maior o escore, maior é o comprometimento funcional, contrário do Índice de Barthel, que varia de 0 a 100 e altos valores do índice indicam menor comprometimento funcional; a Medida da Função Motora $(\mathrm{MFM})^{9}$ avalia o comprometimento funcional na posição de bipedestação e transferências, motricidade axial e proximal e motricidade distal; a Escala Funcional de Brooke ${ }^{12}$ avalia grau de força muscular em membros superiores e inferiores, de forma segmentada, atividade funcional para membros superiores e função pulmonar e a Escala de Vignos ${ }^{13}$ avalia atividade funcional em membros 
inferiores de forma classificatória. Estas escalas não abrangem a atividade funcional proposta neste estudo, o sentar e levantar do solo, e ainda, são pouco úteis para avaliar detalhadamente a função, dificultando a investigação da real progressão funcional relacionada com a doença e a decisão clínica.

Vignos et $\mathrm{al}^{13}$, relatam que as atividades funcionais como a marcha, subir e descer escadas, sentar e levantar da cadeira e do solo são essenciais na avaliação de estadiamento dos portadores de DMD. Scott e Mawson ${ }^{14}$ sugerem a criação de escalas que avaliem essas atividades separadamente e que descrevam mudanças na habilidade funcional.

Estudos que explorem a análise do movimento de sentar e levantar do solo são necessários com o intuito de informar detalhes da funcionalidade do paciente permitindo o acompanhamento da doença ao longo do tempo.

A avaliação dinâmica inclui a análise de atividades funcionais como o andar, subir e descer escada, rolar, sentar e levantar da cadeira e do solo, que são realizados por meio de observação direta. Muitos pesquisadores que estudam atividades funcionais utilizam a filmagem associada à observação sistematizada para gerar dados e informações ${ }^{15-17}$. Métodos mais sofisticados de análise de movimento, como a eletromiografia ${ }^{18}$, são de difícil acesso na prática clínica e encarecem demasiadamente a avaliação de rotina.

Este estudo teve como objetivos construir uma escala de avaliação funcional da atividade de sentar e levantar do solo para crianças com DMD não-cadeirantes e testar sua confiabilidade intra-examinador e interexaminadores. Posteriormente avaliou-se a correlação dos escores obtidos com escores de outra escala muito utilizada em DMD, a Escala Funcional de Vignos, a idade e o tempo de realização da atividade. 


\section{OBJETIVO}

Este estudo teve como objetivos:

1. Construir uma escala de avaliação funcional da atividade de sentar e levantar do solo para crianças com DMD não-cadeirantes,

2. Testar a confiabilidade da escala intra-examinador e interexaminadores,

3. Avaliar a correlação dos escores obtidos com os encontrados utilizando a Escala Funcional de Vignos, a idade e o tempo de realização da atividade. 


\section{REVISÃO DA LITERATURA}

\subsection{DISTROFIA MUSCULAR DE DUCHENNE (DMD)}

As distrofias musculares são definidas como miopatias progressivas, geneticamente determinadas, degenerativas e irreversíveis ${ }^{19}$. A Distrofia Muscular de Duchenne (DMD) é uma doença neuromuscular recessiva ligada ao cromossomo X, clinicamente caracterizada por fraqueza muscular progressiva, com início na infância levando a morte em torno dos 20 anos de idade. É a forma mais comum das distrofias musculares ${ }^{20}$. Afeta predominantemente crianças do sexo masculino e a ocorrência se dá em 1/3500 nascidos vivos. No sexo feminino ocorre a inativação de um dos cromossomos $\mathrm{X}$, assim, as mulheres podem ser somente portadoras do gene da distrofia, não apresentando a patologia. Um terço dos casos são de mutações novas e dois terços são familiais, isto é, herdados de mães portadoras do gene da distrofia ${ }^{21}$.

\subsubsection{Fisiopatologia}

As distrofias musculares são um grupo heterogêneo de doenças genéticas, caracterizadas pela perda progressiva de força muscular e sua integridade. Ocorrem ciclos sucessivos de degeneração e regeneração de fibras musculares e eventualmente resultam em necrose e recolocação do tecido muscular por tecido fibroso. As doenças são classificadas por sua apresentação clínica, distribuição, extensão da fraqueza muscular (algumas formas afetam igualmente o músculo cardíaco), idade de início, progressão e teste de herança. A informação genética contribui para a compreensão da patogênese molecular da distrofia muscular e o desenvolvimento de estratégias a fim de amenizar a doença ${ }^{22}$. 
A DMD é causada por um gene defeituoso mapeado no local Xp21 que deveria produzir uma enzima denominada distrofina ${ }^{23,24}$. A distrofina normalmente localiza-se na superfície da membrana da fibra muscular. Assim, a forma severa de DMD é associada a um defeito genético que impede a produção de quantidades adequadas de distrofina $^{25}$. Sabe-se que a distrofina está ligada ao citoesqueleto da membrana, por meio de glicoproteínas, para formar o complexo distrofinaglicoproteína. Quando este complexo está deficiente, resulta em influxo de cálcio, causando degeneração e morte celular ${ }^{26}$. A falta de distrofina na DMD leva a perda das proteínas associadas ao sarcolema, perda da ligação entre o citoesqueleto subsarcolemal e a matriz extracelular, com instabilidade do sarcolema, sensibilidade aos traumatismos causados pelo exercício, sobrecarga de cálcio intramuscular e necrose das fibras musculares, resultando em perda de força muscular ${ }^{27}$.

A alteração inicial na fibra muscular é o edema (que precede a atrofia), seguida da degeneração. Há evidências de necrose segmentar de fibras musculares em grupos focais nas formas mais progressivas, acompanhando a regeneração da fibra muscular ${ }^{19}$. Esta regeneração é comum nos estágios iniciais ${ }^{28,29}$, mas torna-se progressiva e ineficiente com o passar do tempo, ocorrendo a deposição de gordura entre as fibras musculares em degeneração e um discreto infiltrado inflamatório ${ }^{30}$ (Fig.1).

A atrofia é identificada nos tipos de fibras I, IIA e IIB. Nos fusos musculares ocorrem alterações degenerativas, atrofia, desaparecimento de fibras intrafusais e espessamento da cápsula do fuso. A sua inervação permanece normal ${ }^{30}$. 


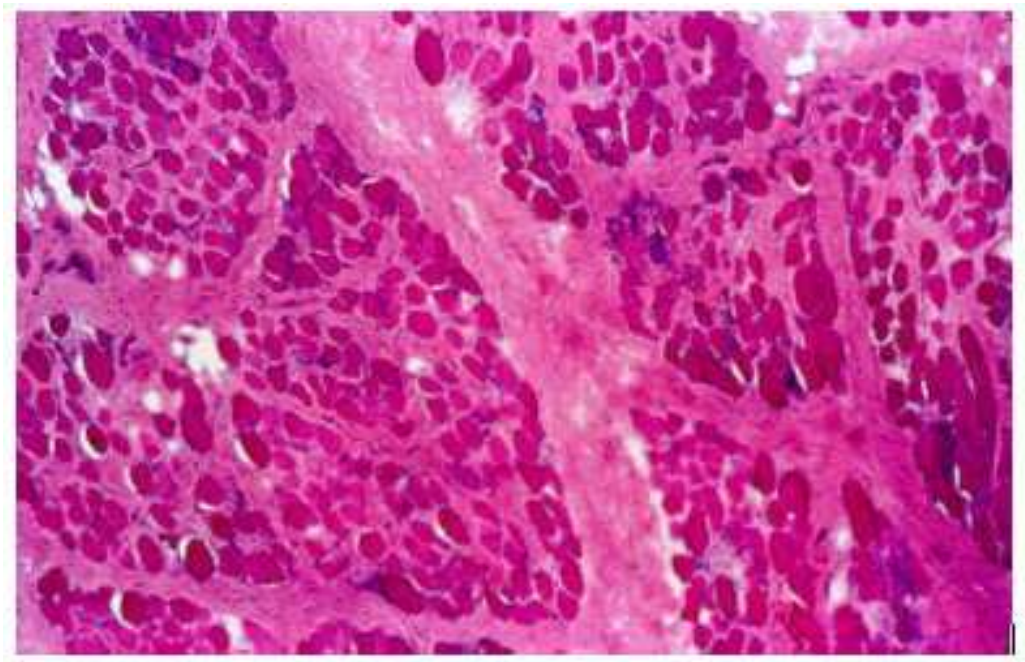

Figura 1. Corte histológico de tecido muscular de paciente com DMD. Observa-se variação no tamanho das fibras, necrose e proliferação de tecido conjuntivo (http://www.scn.es)

\subsubsection{Sinais e sintomas}

As queixas principais da maioria dos pacientes com DMD são com relação à marcha, apresentando freqüentes quedas e dificuldades com escadas. A média de idade para o diagnóstico está entre 4 e 5 anos quando a fraqueza muscular proximal é suficientemente severa para produzir déficit na marcha e dificuldade para se elevar do solo ${ }^{31-33}$. No exame físico pode-se encontrar fraqueza muscular proximal leve em membros inferiores com sinal de Gowers, encurtamento do tendão aquileu e reflexos tendíneos nos arcos ainda presentes. Há hiperlordose lombar compensatória que desaparece quando a criança se senta. A fraqueza do glúteo máximo, responsável pela extensão do quadril, resulta numa inclinação anterior da pelve (anteversão), desenvolvendo a hiperlordose lombar. Associado a isto, há um desequilíbrio de forças entre dorsiflexores e flexores plantares. Por estes motivos, a criança passa a 
adotar a marcha anserina para manter o equilíbrio. Observa-se ainda quedas freqüentes, dificuldade em pular, correr, subir escadas ou se elevar do solo, podendo se observar a realização da manobra de Gowers. Esta manobra é frequentemente observada em pessoas com miopatias (principalmente em DMD), onde, se elevam do solo escalando seus $\mathrm{MMII}^{34}$. A criança se utiliza desta manobra por fraqueza de extensores de quadril e joelhos ${ }^{35}$. Os músculos gastrocnêmios são hipertrofiados devido à substituição das fibras musculares por tecido fibroso. Além da fraqueza muscular, um comprometimento mental pode estar presente em $\mathrm{DMD}^{36}$. Aproximadamente $33 \%$ dos pacientes têm um quociente de inteligência abaixo de $75^{37}$. Devido à doença muscular ser de natureza progressiva, há um declínio linear, fazendo com que as crianças se limitem à cadeira de rodas por volta dos 9 anos e meio de idade $^{38}$. A escoliose é uma complicação freqüente podendo levar à intervenção cirúrgica. A hipoventilação noturna pode ser o primeiro sinal de insuficiência respiratória. Se presente, a criança desperta freqüentemente, tem receio de dormir e apresenta dor de cabeça ao amanhecer. Atualmente $25 \%$ dos pacientes apresentam sinais de cardiomiopatia antes dos 6 anos e 59\% entre 6 e 10 anos não apresentam sintomas ${ }^{39}$. Eventualmente os pacientes com DMD morrem por insuficiência respiratória devido à infecção ou broncoaspiração, ou por arritmia cardíaca. Os pacientes que fazem uso precoce de ventilação mecânica não-invasiva têm uma expectativa média de vida de 25 anos e aqueles que não recebem ventilação, de $19 \operatorname{anos}^{40}$. 


\subsubsection{Diagnóstico}

A confirmação de DMD depende de testes diagnósticos, como, ausência de distrofina na biópsia muscular ou presença de deleção da distrofina no cromossomo Xp21. Deve-se suspeitar de DMD quando níveis de creatino-fosfokinase (CK) estão elevados em meninos com atraso no desenvolvimento ${ }^{41,42}$. Em todos os pacientes com DMD os níveis séricos de CK estão aumentados cerca de 10 vezes sobre o limite superior normal desde o nascimento. Após os 5 anos de idade os níveis declinam lentamente.

Geralmente a biópsia muscular é realizada nos músculos quadríceps, gastrocnêmios ou deltóide. As fibras musculares se encontram necrosadas e com sinais de regeneração, variabilidade no diâmetro da fibra, como, hipertróficas e diminuídas $^{43}$. A eletromiografia (EMG) é realizada como exame complementar no diagnóstico de $\mathrm{DMD}$, onde, os potenciais de ação são menores quanto à duração e amplitude. Observa-se uma perda generalizada da atividade da fibra muscular com redução da extensão da unidade motora ${ }^{44}$. A histoquímica muscular, estudos de inervação muscular, microscopia eletrônica, eletrocardiografia e tomografia computadorizada podem fornecer informações adicionais para uma melhor compreensão sobre a evolução da DMD, bem como no auxílio do diagnóstico diferencial $^{45}$. 


\subsubsection{Tratamento}

No momento não há cura para DMD e os objetivos do tratamento visam manter a função e fornecer suporte psicológico para a criança e seus familiares ${ }^{8}$. Os corticósteróides melhoram a força muscular e função nas crianças com DMD tratadas dos 6 meses aos 2 anos, segundo estudo controlado e randomizado ${ }^{46,47}$. A dose eficaz é de $0,75 \mathrm{mg} / \mathrm{Kg} / \mathrm{dia}^{48}$. Não se sabe ao certo se a continuidade de corticosteróides na fase adulta é indicada, pelos riscos que geram ao longo do tempo, como, ganho de peso, facies de Cushing, baixa estatura, hipertensão, hiperglicemia, catarata e osteoporose. Muitos pacientes interrompem o uso de prednisona principalmente pelo ganho de peso, que dificulta as transferências e cuidados. Parâmetros desenvolvidos pelo Comitê de qualidade da Academia Americana de Neurologia recomenda a diminuição da prednisona para $0.5 \mathrm{mg} / \mathrm{kg} / \mathrm{dia}$ se o peso ganho for maior que $20 \%$ do peso normal estimado para a altura, se ocorrer durante 12 meses. Se o ganho de peso continuar, diminuir para $0.3 \mathrm{mg} / \mathrm{kg} / \mathrm{dia}^{49}$. Um estudo avaliou 30 pacientes utilizando prednisona durante 10 anos e encontrou a melhor dose, $0.36 \mathrm{mg} / \mathrm{kg} / \mathrm{dia}^{50}$.

A fisioterapia deve priorizar os exercícios diários de alongamento passivo em MMSS e MMII a fim de prevenir contraturas. A utilização de órteses também é indicada para manter os pés em posição neutra durante a noite. A maioria das pessoas com DMD morrem por complicações referentes à fraqueza de músculos respiratórios. Isto inclui progressivo padrão ventilatório restritivo, hipoventilação crônica e infecções pulmonares. A fraqueza dos músculos expiratórios resulta em diminuição do volume pulmonar e a tosse é ineficaz para expectoração de secreções, aumentando o risco de pneumonias ${ }^{51,52}$. Há evidências de que o uso de ventilação por pressão positiva não invasiva é benéfico para esta população, melhorando a hipercapnia, hipoxemia ${ }^{53,54}$, sobrevida $^{55}$, qualidade de vida ${ }^{54}$ e também, pode atrasar o declínio da função pulmonar ${ }^{56}$. 


\subsection{Avaliação funcional de pessoas com DMD}

Os protocolos ou escalas de avaliação neuromuscular mais utilizados em pessoas com DMD possuem dados amplos e são limitados no que se refere à avaliação detalhada da função. A avaliação neuromuscular inclui a forma estática e dinâmica. A avaliação neuromuscular dinâmica inclui as atividades funcionais como o andar, subir e descer escada, rolar, sentar e levantar da cadeira e do solo ${ }^{57}$.

Na literatura não há estudos que descrevam e avalie a manobra de Gowers em portadores de distrofia muscular de Duchenne, tampouco, a passagem de decúbito dorsal para bipedestação e a passagem de bipedestação para sedestação no solo em crianças saudáveis. Em um estudo com jovens adultos, Araujo ${ }^{17}$ utiliza esses testes para avaliar força muscular, flexibilidade e coordenação motora.

Algumas escalas que avaliam função motora são validadas para DMD, como: $\checkmark \quad$ Egen Klassifikation (EK) - esta escala foi desenvolvida na Dinamarca e já validada em português. Visa quantificar o grau de limitação funcional em pacientes com DMD no estágio avançado da doença. A escala EK é dividida em dez categorias, cada uma com quatro alternativas, que fornecem escores parciais e varia entre 0 e 3 . Um escore total é obtido pela soma dos escores parciais (entre 0 e 30 ). Quanto maior o grau de acometimento funcional, maior o escore obtido (Anexo A).

$\checkmark \quad$ Índice de Barthel - É uma escala muito utilizada clinicamente no Brasil e mundialmente é aplicada em diversas doenças, como, esclerose múltipla, AVC, lesões medulares, espinha bífida, entre outras. Em DMD, um estudo afirmou ser um instrumento válido para ser empregado na avaliação das limitações funcionais para atividades de vida diária $^{58}$. É composto por dez itens, que avaliam a habilidade para 
alimentar-se, vestir-se, higiene pessoal e alimentação. Os escores parciais variam entre 0 e 10 ou 0 e 15 . O escore total varia entre 0 e 100 . Altos valores do índice de Barthel indicam menor comprometimento funcional (Anexo B).

$\checkmark \quad$ Medida da Função Motora (MFM) - A Medida da Função Motora é uma escala muito utilizada em pacientes com doenças neuromusculares e já é validada para o português. A MFM mede ao longo do tempo a mudança das capacidades motoras funcionais do paciente. Avalia o comprometimento funcional na posição de bipedestação e transferências, motricidade axial e proximal e motricidade distal. A escala compreende 32 itens, alguns estáticos, outros dinâmicos. Os itens são testados nas posições deitado, sentado ou em pé, e são divididos em três dimensões.

D1: posição em pé e transferências, com 13 itens.

D2: motricidade axial e proximal, com 12 itens.

D3: motricidade distal com 7 itens, dos quais 6 se referem ao membro superior.

Cada item é graduado numa escala de 4 pontos, de modo que:

0 - não pode iniciar a tarefa ou não pode manter a posição inicial

1 - realiza parcialmente o exercício

2 - realiza incompletamente o movimento solicitado ou completamente, mas de forma imperfeita (compensação, duração e manutenção insuficiente da posição, lentidão, falta de controle do movimento)

3 - realiza completamente, "normalmente" o exercício, com movimento controlado, perfeito e realizado com velocidade constante.

A nota final é obtida por porcentagem, quanto maior a porcentagem maior o desempenho da pessoa (Anexo C). 
$\checkmark \quad$ Escala de Vignos - A escala de Vignos foi elaborada em 1960, por Vignos e Archibald. Avalia funcionalidade e é utilizada com freqüência para graduar fases da DMD. Essa escala foi feita para avaliar a qualidade do movimento, porém, de forma classificatória. A avaliação é baseada nas habilidades de deambulação, subir escada e sentar na cadeira (Anexo D). O tempo de realização das atividades também é preconizado por Vignos, com o objetivo de avaliar a performance muscular que dependem de adequado sinergismo e estabilidade dos músculos ${ }^{13}$. Nessa escala quanto maior a nota obtida, pior é o desempenho motor (Anexo D). 


\section{MÉTODO}

Este estudo foi aprovado pela Comissão de Ética para Análise de Projetos de Pesquisa do Hospital das Clínicas e da Faculdade de Medicina da Universidade de São Paulo, processo número 837/05.

\subsection{Amostra}

Para a construção da escala foi estudada, por meio de observação sistematizada de registro em filme, 120 execuções da atividade de sentar e levantar do solo, obtido com a participação de 30 crianças com diagnóstico molecular de DMD, não cadeirantes, com idade entre 5 e 12 anos. Cada filme foi coletado num período de um ano com intervalo de três meses entre cada registro.

\subsection{Local}

Laboratório de Fisioterapia e Comportamento do Curso de Fisioterapia da Faculdade de Medicina da Universidade de São Paulo.

\subsection{Material}

Foi utilizado uma televisão 24 polegadas, videocassete, cronômetro, fichas para observação, 120 registros em filmes com crianças com de DMD realizando atividades funcionais. 


\subsection{Procedimentos:}

\subsubsection{Construção da escala}

\subsubsection{Versão inicial}

A partir de estudo de análise de movimento por meio de observação indireta (filmes) Escorcio et $\mathrm{al}^{59}$ descreveram o movimento de sentar e levantar do solo em crianças saudáveis e foi possível compreender o padrão de normalidade estabelecido para esta atividade. Alguns autores utilizam a avaliação desta atividade em adultos $^{17,60}$. Este estudo gerou um roteiro com sequiência de movimentos a serem observados em crianças durante a realização desta atividade.

Utilizando este roteiro, foram observados 120 registros filmados de crianças com DMD, com idade variando de 5 a 12 anos, realizando as atividades de sentar e levantar do solo, sendo que, para se levantar do solo todas as crianças realizaram a manobra de Gowers, que é uma manobra característica em miopatias ${ }^{61,62}$, ou seja, o levantar miopático do solo. Os filmes utilizados neste estudo fazem parte de um banco de dados coletado no Laboratório de Miopatias do Instituto de Biociências da Universidade de São Paulo . Considerando-se as informações coletadas no estudo do movimento caracterizado nas crianças saudáveis e nos 120 registros, elaborou-se os critérios de avaliação funcional da atividade de sentar e levantar do solo para portadores de DMD não-cadeirantes. Estes critérios foram organizados de acordo com o grau de dificuldade de execução, gerando a EAF-2 - primeira versão, sendo 
esta, integrante de um estudo que compõe outras escalas de avaliação, como a EAF1, que avalia o sentar e levantar da cadeira, EAF-3 avalia o subir e descer escadas e a EAF-4, avalia a marcha.

\subsubsection{Versão final}

As fichas de avaliação e o manual de instrução foram submetidos a 10 peritos, independentes dos examinadores, com titulação mínima de mestre ${ }^{63}$ e com experiência prévia em DMD, para que avaliassem todos os itens das fichas e determinassem a pertinência destes e a adequação com o relatado no manual de instrução.

Após os pareceres dos peritos, com sugestões, foi realizada a correção e gerada a escala final e seu manual, que devem ser utilizados para avaliação por meio de observação, de preferência de material permanente (filme). A escala gera um escore final numérico. A parte da escala que avalia o levantar do solo possui cinco fases, a saber: decúbito dorsal para flexão de tronco e/ou decúbito lateral, posição sentada, gato e/ou ajoelhado, posição de quadrupedia e bipedestação, sendo que, o melhor desempenho tem um escore 0 (zero) e o pior desempenho tem escore 15 (Tabela 1). A parte da escala que avalia o sentar no solo a partir da bipedestação possui três fases, a saber: flexão de tronco, flexão de joelhos e tornozelos e posição sentada, sendo que, o melhor desempenho tem escore 0 (zero) e o pior desempenho tem escore 10 (Tabela 2). A escala é acompanhada pelo manual de instrução detalhado de cada fase e da pontuação a ser aplicada (Anexo E e F). 
Tabela 1: EAF2 - DMD: Levantar do solo

Nota

\begin{tabular}{|c|c|c|}
\hline \multirow[t]{4}{*}{ De DD para flexão de tronco } & - sem apoio & 0 \\
\hline & - com apoio de MS & 1 \\
\hline & . com apoio de MMSS & 2 \\
\hline & $\begin{array}{l}\text { caso passe DD direto } \\
\text { para sentado e use o } \\
\text { apoio de MMSS }\end{array}$ & 0 \\
\hline
\end{tabular}

E / OU

\begin{tabular}{|c|c|c|c|}
\hline De DD para DL & $\begin{array}{l}\text { ( ) } \mathrm{P} \quad(\text { ) } \mathrm{A} \\
\mathrm{P}=3 \text { pontos } \\
\mathrm{A}=0 \text { ponto }\end{array}$ & & \\
\hline \multirow[t]{3}{*}{ Passa para sentado } & \multirow[t]{3}{*}{$\begin{array}{l}\text { ( ) SIM } \longrightarrow \\
\text { ( ) NÃO - zero ponto }\end{array}$} & $\begin{array}{l}\text { Senta e se estabiliza sem } \\
\text { apoio de MMSS }\end{array}$ & 1 \\
\hline & & $\begin{array}{l}\text { - senta e se estabiliza } \\
\text { com apoio de MS }\end{array}$ & 2 \\
\hline & & $\begin{array}{l}\text { - senta e se estabiliza } \\
\text { com apoio de MMSS }\end{array}$ & 3 \\
\hline $\begin{array}{l}\text { Passa para gato } \\
(\text { Fase } 3)\end{array}$ & & - com apoio de MMSS & 0 \\
\hline
\end{tabular}

E / OU

\begin{tabular}{|c|c|c|c|}
\hline Passa para ajoelhado & & $\begin{array}{l}\text { Precisa de ponto de } \\
\text { apoio externo }\end{array}$ & 1 \\
\hline \multirow{3}{*}{$\begin{array}{l}\text { Posição de quadrupedia } \\
\text { (Fase 4) }\end{array}$} & & - com apoio de MMSS & 0 \\
\hline & & $\begin{array}{l}\text { Precisa de ponto de } \\
\text { apoio externo }\end{array}$ & 2 \\
\hline & & $\begin{array}{l}\text { * NÃO REALIZA } \\
\text { QUADRUPEDIA }\end{array}$ & 6 \\
\hline \multirow[t]{5}{*}{$\begin{array}{l}\text { Passagem de quadrupedia } \\
\text { para bipedestação }\end{array}$} & \multirow{5}{*}{$\begin{array}{l}\text { Obs: se levantar sem } \\
\text { escalar as pernas, será } \\
\text { considerado nota zero } \\
(0) \text {. }\end{array}$} & $\begin{array}{l}\text { - escala com apoio de } \\
\text { MS no joelho }\end{array}$ & 1 \\
\hline & & $\begin{array}{l}\text { Escala com apoio de } \\
\text { MMSS em joelho e coxa }\end{array}$ & 2 \\
\hline & & $\begin{array}{l}\text { Escala com apoio de } \\
\text { MMSS em perna, joelho } \\
\text { e coxa }\end{array}$ & 3 \\
\hline & & $\begin{array}{l}\text { Precisa de ponto de } \\
\text { apoio externo }\end{array}$ & 4 \\
\hline & & $\begin{array}{l}\text { PÁRA NA POSIÇÃO } \\
\text { DE APOIO } \\
\text { EXTERNO }\end{array}$ & 5 \\
\hline
\end{tabular}

NOTA OBTIDA:

\begin{tabular}{|l|l|}
\hline TOTAL & \\
\hline$\Delta \mathbf{t}$ & \\
\hline
\end{tabular}


Tabela 2: EAF2 - DMD - Sentar no solo

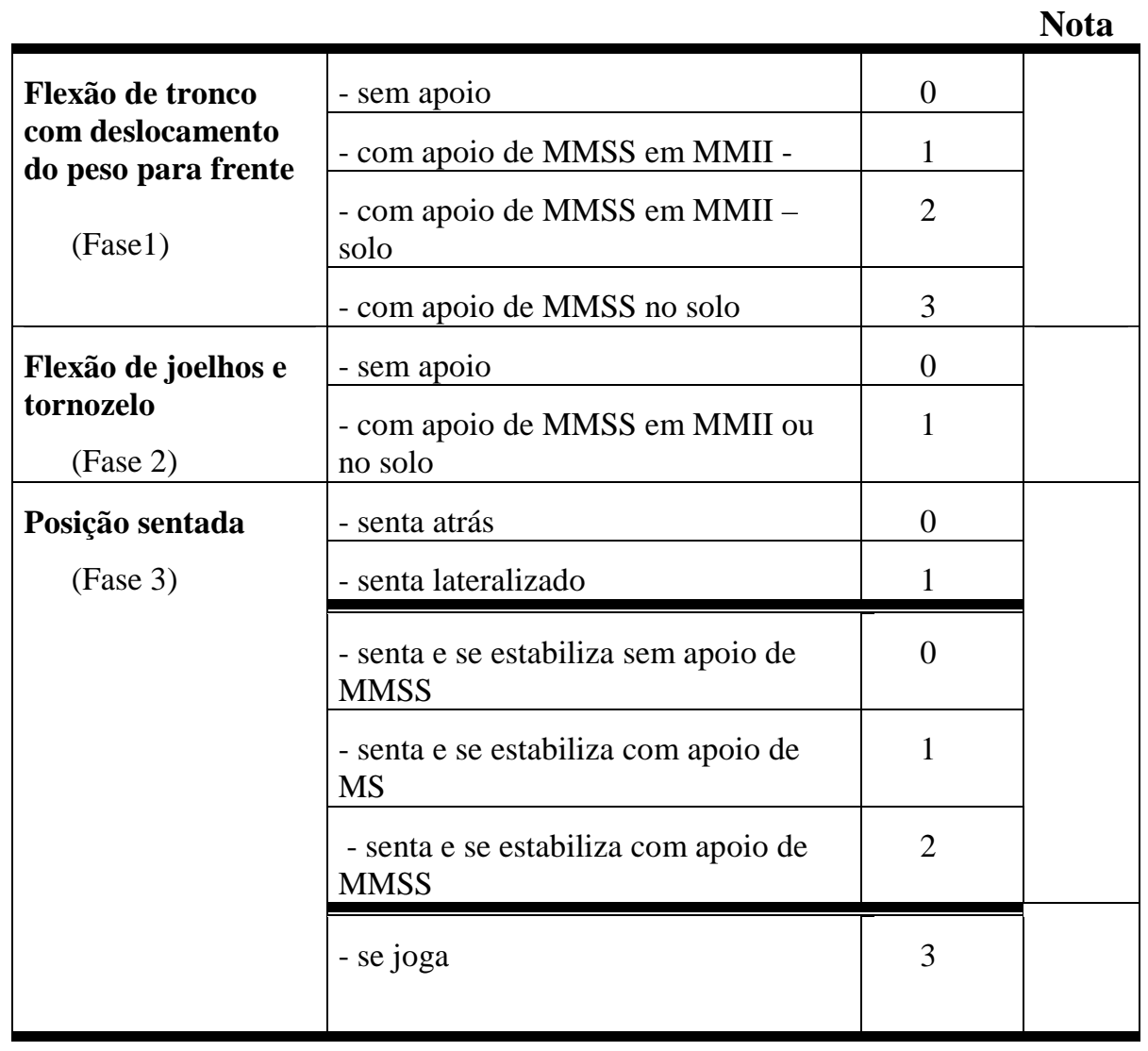

NOTA OBTIDA:

TOTAL

$\Delta \mathbf{t}$

\subsubsection{Análise de repetibilidade e reprodutibilidade}

A escala foi submetida à análise de confiabilidade intra-examinador (repetibilidade) e interexaminador (reprodutibilidade). Para análise de confiabilidade na situação interexaminadores foram selecionados dois examinadores independentes, com atuação em fisioterapia pediátrica há pelo menos dois anos, formação mínima de mestre, e experiência com crianças de DMD. Foram utilizados 30 filmes de 30 
crianças com DMD realizando as atividades de sentar e levantar do solo, onde, foram filmadas durante um ano, em quatro eventos independentes de coleta de dados, realizados com intervalo de 3 meses entre as coletas (gerando 120 registros), sendo avaliado, para o estudo de confiabilidade, o primeiro registro das atividades de cada filme. Os examinadores receberam os filmes, as fichas de avaliação da escala e o manual de normas para preenchimento da escala. Os filmes foram avaliados pelos examinadores em laboratórios diferentes, com equipamentos diferentes, sem que houvesse conhecimento entre eles dos resultados ${ }^{64}$. Para o estudo de confiabilidade intra-examinador, cada registro foi avaliado em duas ocasiões diferentes, com intervalo de tempo de quatro semanas, para que o examinador não memorizasse os resultados ${ }^{65,66}$.

Para avaliar a confiabilidade da escala, foi utilizado o teste de aderência Shapiro Wilk, em seguida, foi realizado análise de variância ANOVA two-way e one-way e foi possível verificar os Índices de Correlação Intra-Classe (ICC) nas formas 3.1 e 2.1, segundo Weir $^{66}$ entre os dados analisados. Para avaliar a confiabilidade, considerando cada uma das 8 fases da escala, utilizou-se o Coeficiente Kappa Ponderado. Foi adotado nível de significância $\alpha=0,05$. Para as análises de correlações entre as variáveis utilizou-se o teste não paramétrico de Spearman, o qual permitiu identificar as variáveis que mais se correlacionaram. 


\section{RESULTADOS}

\subsection{Confiabilidade intra e interexaminador}

Foram avaliados 120 filmes com crianças com DMD, realizando o sentar e levantar do solo, com idade média de 7,4 \pm 2,2 (5-12 anos), peso médio de 40,8 \pm $10,4 \mathrm{Kg}$ e altura $1.39 \pm 0.17 \mathrm{~m}$, com diagnóstico molecular ou por DNA de DMD. A população estudada apresentou escore de Vignos de 2,48 \pm 1,02, com escore mínimo de 0 e máximo de 3, sendo que os valores variam de 0 a 10 . Encontrou-se na avaliação funcional da atividade do levantar do solo, utilizando a EAF-2, média de 8 $\pm 4,59$, com escore mínimo de 1 e máximo de 14 e para a atividade de sentar no solo, média de 5,1 $\pm 2,59$, escore mínimo de 0 e máximo de 9 .

A tabela 3 mostra os ICCs das análises de repetibilidade e reprodutibilidade das variáveis em questão e a classificação de acordo com Wahlund et $\mathrm{al}^{67}$, onde ICCs $<0,70=$ não aceitável; $0,71<$ ICCs $<0,79=$ aceitável; $0,80<$ ICCs $<$ O,89 = muito bom; ICCs $>0,90=$ excelente, bem como o valor de $\mathrm{p}$.

Observa-se que o escore total do levantar e sentar das variáveis avaliadas pela repetibilidade (intra-avaliador) apresentou muito boa confiabilidade, demonstrando uma precisão da escala de avaliação do levantar e sentar para portadores de distrofia muscular de Duchenne (Tabela 3). Pode-se observar também que as variáveis analisadas pela reprodutibilidade apresentaram excelente concordância entre os examinadores tanto para o levantar quanto para o sentar de portadores de distrofia muscular de Duchenne. 
Tabela 3 - Análise de repetibilidade (intra-examinador) e reprodutibilidade (interexaminador) das fases do sentar e levantar em portadores de distrofia muscular de Duchenne.

\begin{tabular}{lccc}
\hline \hline Variáveis & ICC & Classificação & p-valor \\
\hline \hline $\begin{array}{c}\text { Intra-examinador } \\
\text { Sentar }\end{array}$ & 0,89 & Muito bom & 0,886 \\
Intra-examinador & 0,84 & Muito bom & 0,676 \\
Levantar & & & \\
Interexaminadores & & & 0,789 \\
Sentar & 0,93 & Excelente & \\
Interexaminadores & & & 0,992 \\
Levantar & 0,92 & Excelente & \\
\hline \hline
\end{tabular}

Ficou evidenciada pouca variabilidade entre os examinadores na análise de repetibilidade e reprodutibilidade das variáveis em questão.

Considerando as 8 fases da escala, utilizou-se o Coeficiente Kappa ponderado para análise interexaminadores, onde, variou de 0,77 a 1,00 (confiabilidade excelente para 5 fases e substancial para 3 fases) e na análise intra-examinador variou de 0,80 a 1,00 (confiabilidade excelente para 6 fases e substancial para 2 fases), onde $<0,20=$ pobre, $0,21-0,40=$ concordância ligeira, $0,41-0,60=$ concordância considerável, $0,61-0,80=$ concordância substancial e $>0,81=$ concordância excelente, de acordo com Landis \& $\mathrm{Koch}^{68}$. Os avaliadores apresentaram concordância substancial e excelente nas análises de repetibilidade e reprodutibilidade, demonstrando que a escala apresenta confiabilidade satisfatória. 
Houve um índice de correlação razoavelmente satisfatório somente entre algumas variáveis. A correlação apresentou-se boa entre as variáveis idade x Escala de Vignos $(r=0,58)$ e levantar x Escala de Vignos $(r=0,56)$, enquanto que nas variáveis restantes a correlação foi baixa, destacando-se entre as variáveis sentar $\mathrm{x}$ idade $(r=0,11)$ e sentar $\mathrm{x}$ Escala de Vignos, onde a correlação foi $(r=0,21)$. Em relação às correlações entre a avaliação do sentar e levantar e o tempo de realização dessas atividades somente houve correlação satisfatória entre o tempo e a escala de avaliação do levantar (ICC $=0,79),(p=0,001)$, pois em relação ao sentar não foi evidenciada nenhuma correlação, visto o índice negativo de correlação da mesma $(\mathrm{ICC}=-0,25, p=0,158)$. 


\section{DISCUSSÃO}

A EAF-2 permite avaliar os déficits funcionais e as possíveis compensações em crianças com DMD. O escore é reproduzível e os valores de ICC e Kappa encontrados foram muito bons ou excelentes.

Pela escassez de estudos na literatura sobre a descrição do movimento de sentar e levantar do solo em crianças saudáveis, Escorcio et al $^{59}$ fizeram um estudo piloto a fim de observar como as crianças realizavam essas atividades, e, observaram que o sobrepeso associado a déficit de força muscular são prejudiciais ao desempenho destas manobras. Araujo ${ }^{17}$, num estudo com jovens adultos, relata que as ações de sentar e levantar do solo demandam maiores níveis de força muscular, flexibilidade e coordenação motora, e, o excesso de peso interfere negativamente no desempenho dessas tarefas, além da flexibilidade e a potência muscular serem fatores intervenientes, corroborando o estudo de Escorcio et al. Os testes de sentar-levantar do solo indicam um desempenho mais completo da aptidão funcional do indivíduo jovem $^{60}$.

Na DMD ocorre fraqueza muscular progressiva, levando a uma disfunção de equilíbrio e coordenação, prejudicando, com a evolução da doença, a realização de atividades funcionais ${ }^{69-71}$.

A amostra de 120 registros filmados, com atividades de sentar e levantar do solo, executadas por 30 crianças com DMD, avaliadas a partir de guia de normalidade, foi suficiente para gerar uma escala com grande detalhamento cinesiológico desta atividade funcional. Os examinadores relataram que foi possível detectar e registrar todos os movimentos realizados pelas crianças durante a avaliação. 
A EAF-2, gerada neste estudo, é suficiente para detectar a severidade do déficit motor, especificamente em crianças com DMD, o contrário do que foi observado nas escalas validadas para DMD, que avaliam comprometimento funcional e força muscular de forma segmentada. Estas escalas fornecem uma abordagem geral do paciente, mas não abrange as atividades de sentar e levantar do solo. Sabendo que, a avaliação de habilidades funcionais é um indicador prognóstico de confiança ${ }^{9}$, a EAF-2 pode fornecer subsídios para a intervenção e orientação fisioterapêuticas.

A ótima confiabilidade intra-examinador e interexaminador dos escores das escalas de sentar e levantar do solo, foi possível devido à fácil aplicação e de possuir um manual claro que oriente em relação à avaliação e pontuação de cada item. Os valores de ICC e Kappa encontrados, ainda podem ser justificados devido à experiência dos examinadores com este tipo de população. Pode estar também relacionado ao fato de as compensações realizadas por esta população serem bem características nestas atividades funcionais. Pode-se dizer que a baixa correlação encontrada na atividade de sentar no solo com a idade, tempo e dados obtidos com a Escala de Vignos, se deu pela fraqueza muscular exacerbada dos músculos extensores de tronco, fazendo com que as crianças se joguem para frente, não conseguindo, no entanto, frear o movimento. Observamos como limitações do estudo, o fato de ter sido realizado em um único centro, não apresentar comparação com padrão ouro, a exemplo da EMG ou análise cinemática, e ainda, os examinadores serem experientes e treinados. Há expectativas de aplicação da escala em outros centros e também a criação de um software de coleta de dados e geração de laudo, inclusive comparativo. 


\section{CONCLUSÃO}

A EAF-2 é um instrumento de avaliação confiável que permite avaliar a atividade de sentar e levantar do solo em crianças com DMD de forma detalhada e operacionalizada. 


\section{ANEXOS}

\section{Anexo A - Egen Klassifikation}

1. Habilidade para o uso da cadeira de rodas

0 . Capaz de usar uma cadeira de rodas manual no plano, progredindo pelo menos 10 metros em menos de um minuto.

1. Capaz de usar uma cadeira de rodas manual no plano, progredindo 10 metros em mais de um minuto.

2. Incapaz de usar uma cadeira de rodas manual, necessitando de uma cadeira de rodas elétrica.

3. Faz uso de uma cadeira elétrica, mas ocasionalmente apresenta dificuldades para realizar curvas.

2. Habilidade de transferência de cadeira de rodas

0 . Capaz de sair da cadeira de rodas sem ajuda.

1. Capaz de sair da cadeira de rodas de maneira independente, mas com necessidade de dispositivo auxiliar.

2. Necessita assistência para sair da cadeira de rodas, com ou sem uso de dispositivos auxiliares.

3. Necessita ser levantado com suporte da cabeça quando saindo da cadeira de rodas.

3. Habilidade de permanecer em pé

0 . Capaz de manter-se em pé com os joelhos apoiados, assim como quando usando muletas.

1. Capaz de manter-se em pé com joelhos e quadris apoiados, assim como quando utilizando dispositivos auxiliares.

2. Capaz de manter-se em pé com apoio para todo o corpo.

3. Incapaz de ficar em pé; presença de contraturas acentuadas.

4. Habilidade de balançar-se na cadeira de rodas

0. Capaz de assumir sozinho uma posição vertical a partir de uma flexão ventral completa com a ajuda das mãos.

1. Capaz de mover a porção superior do corpo mais do que 30 graus a partir da posição sentada em todas as direções, mas incapaz de assumir sem ajuda a posição vertical a partir de uma flexão ventral completa.

2. Capaz de mover a porção superior do corpo menos de 30 graus de um lado a outro.

3. Incapaz de modificar a posição da parte superior do corpo; não consegue sentar sem o apoio total do tronco e cabeça.

5. Habilidade de movimentação dos braços.

0. Capaz de elevar os braços acima da cabeça com ou sem movimentos compensatórios.

1. Incapaz de levantar os braços acima da cabeça, mas capaz de elevar os antebraços contra a gravidade como, por exemplo, a mão até a boca, com ou sem apoio dos cotovelos.

2. Incapaz de elevar os antebraços contra a gravidade, mas capaz de usar as mãos contra a gravidade quando o antebraço está apoiado.

3. Incapaz de mover as mãos contra a gravidade, mas capaz de usar os dedos.

6. Habilidade de usar as mãos e braços para comer

0. Capaz de cortar a carne em pedaços e comer com colher e garfo. Pode elevar uma tigela cheia (aproximadamente $250 \mathrm{ml}$ ) até a boca sem o apoio do cotovelo.

1. Come e bebe com o cotovelo apoiado.

2. Como e bebe com o cotovelo apoiado e com a ajuda da mão oposta com ou sem a utilização de dispositivos auxiliares alimentares.

3. Necessita ser alimentado.

7. Habilidade de virar-se na cama

0 . Capaz de virar-se na cama com as roupas de cama.

1. Capaz de virar-se em um divã, mas não na cama.

2. Incapaz de virar-se na cama. Tem que ser virado três vezes ou menos durante a noite.

3. Incapaz de virar-se na cama. Tem que ser virado quatro vezes ou mais durante a noite.

8. Habilidade para tossir

0 . Capaz de tossir efetivamente.

1. Tem dificuldade para tossir e algumas vezes necessita de estímulo manual. Capaz de "limpar a garganta".

2. Sempre necessita de ajuda para tossir. Capaz de tossir somente em certas posições.

3. Incapaz de tossir. Necessita de técnicas de sucção e/ou hiperventilação ou ainda com pressão positiva intermitente para manter as vias aéreas limpas.

9. Habilidade para falar

0 . Fala poderosa. Capaz de cantar e falar alto.

1. Fala normalmente, mas não consegue elevar a sua voz.

2. Fala com voz baixa e precisa respirar após três a cinco palavras.

3. Fala difícil de ser compreendida a não ser pelos parentes próximos.

10. Bem-estar geral

0 . Sem queixas, sente-se bem.

1. Cansa facilmente. Apresenta dificuldades quando repousando em uma cadeira ou na cama.

2. Apresenta perda de peso, perda do apetite. Medo de dormir à noite, dorme mal.

3. Apresenta sintomas adicionais tais como: mudanças de humor, dor de estômago, palpitações, sudorese.

Fonte: Rev Assoc Med Bras 2006 
Anexo B - Índice de Barthel

Activity

Score

Feeding

$\begin{array}{lll}0 & 5 & 10\end{array}$

$0=$ unable

$5=$ needs help cutting, spreading butter, etc., or requires modified diet

$10=$ independent

Bathing

$0=$ dependent

$5=$ independent (or in shower)

Grooming

$0=$ needs to help with personal care

5 = independent face/hair/teeth/shaving (implements provided)

Dressing

$0=$ dependent

$5=$ needs help but can do about half unaided

$10=$ independent (including buttons, zips, laces, etc.)

Bowels

$0=$ incontinent (or needs to be given enemas)

$5=$ occasional accident

$10=$ continent

Bladder

$0=$ incontinent , or catheterized and unable to manage alone

5 = occasional accident

$10=$ continent

\section{Toilet Use}

$0=$ dependent

5 = needs some help, but can do something alone

$10=$ independent (on and off, dressing, wiping)

Transfers (bed to chair and back)

$0=$ unable, no sitting balance

5 = major help (one or two people, physical), can sit

$10=$ minor help (verbal or physical)

$15=$ independent

Mobility (on level surfaces)

$0=$ immobile or $<50$ yards

$5=$ wheelchair independent, including corners, $>50$ yards

$10=$ walks with help of one person (verbal or physical) $>50$ yards

$15=$ independent (but may use any aid; for example, stick) $>50$ yards

Stairs

$\begin{array}{lll}0 & 5 & 10\end{array}$

$0=$ unable

$5=$ needs help (verbal, physical, carrying aid)

$10=$ independent

TOTAL $(0$ - 100)

Fonte: Maryland State Medical Journal 1965 
Anexo C - Medida da função motora para doenças neuromusculares

\begin{tabular}{|c|c|c|c|}
\hline Item & Dimensấo & Posiçăo inicial & Exercicios \\
\hline 1 & $\mathrm{D} 2$ & Supino & Mantenha a cabeça no exxo e faça a rotaçāo completa para cada um dos lados \\
\hline 2 & $\mathrm{D} 2$ & & Levante a cabeça e a mantenha elevada \\
\hline 3 & $\mathrm{D} 2$ & & Flexione o quadril e o joelho além de $90^{\circ}$, deslocando o pé do tapete \\
\hline 4 & D3 & & Perna sustentada pelo examinador: realize a llexāo dorsal do pé em $90^{\circ}$ en relaçāo à perna \\
\hline 5 & $\mathrm{D} 2$ & & Eleve uma das mācs do tapete e toque o ombro oposto \\
\hline 6 & D1 & & $\begin{array}{l}\text { Membros interiores semi-fletidos, patelas para cima, pés apoiados sobre o tapete. Eleve a pelve, } \\
\text { coluna lombar, bacia e coxas, mantendo-as alinhadas e com os pés próximos }\end{array}$ \\
\hline 7 & $\mathrm{D} 2$ & & Passe para decúbito ventral e libere os membros superiores debaixo do corpo \\
\hline 8 & D1 & & Sente-se sobre o tapete, sem apoio dos mentbros superiores \\
\hline 9 & $\mathrm{D} 2$ & Sentado na maca & $\begin{array}{l}\text { Sem apoio dos membros superiores, mantenha a posiçāo sentada e coloque as māos } \\
\text { en contato entre si }\end{array}$ \\
\hline 10 & D2 & & $\begin{array}{l}\text { Bola de tênis en frente ao sujeito, sem apoio dos membros superiores. Incline-se para frente, toque a } \\
\text { bola e depois wolte à posiçāo ereta }\end{array}$ \\
\hline 11 & D1 & & Fique em pé, sem apoio dos membros superiores \\
\hline 12 & D1 & Empé & Sem apoio dos membros superiores, sente-se na caderia, mantendo os pés ligeiramente alastados \\
\hline 13 & $\mathrm{D} 2$ & Sentado na cadeira & $\begin{array}{l}\text { Sem apoio dos membros superiores e sem apoio do enoosto da cadeira, mantenha a posiçāo sen- } \\
\text { tada, oom a cabeça e o tronco al inhados }\end{array}$ \\
\hline 14 & $\mathrm{D} 2$ & Sentado na cadeira & $\begin{array}{l}\text { Com a cabeça posicionada em flexāo: levante a cabeça e a manten ha elevada. } 0 \text { movimento e a } \\
\text { manutençāo devem ser feitos oom a cabeça no eixo }\end{array}$ \\
\hline 15 & D2 & & $\begin{array}{l}\text { Antebrapos apoiados sobre a mesa e cotovelos para fora: coloque ao mesmo tempo as duas māos } \\
\text { sobre a cabeça, ocm a cabeça e o tronco alinhados }\end{array}$ \\
\hline 16 & $\mathrm{D} 2$ & & $\begin{array}{l}\text { Lápis sobre a mesa: toque o lápis com uma das mācs, com o cotowelo en extensāo completa no final } \\
\text { do movimento }\end{array}$ \\
\hline 17 & D3 & & $\begin{array}{l}\text { Dez moedas sobre a mesa: pegue sucessivamente e armazere dez moedas de dez centavos em uma } \\
\text { das māos, no tempo de } 20 \text { segundos }\end{array}$ \\
\hline 18 & D3 & & $\begin{array}{l}\text { Dedo oolocado no centro de um CD-Rom fixo: realize a volta oompleta do CD-Rón com o dedo, semn } \\
\text { apoio da mäo }\end{array}$ \\
\hline 19 & D3 & & $\begin{array}{l}\text { Lápis sobre a mesa: pegue o lápis com uma das mãos; desenhe uma série continua de voltas de } 1 \mathrm{~cm} \\
\text { de altura, dentro de um retângulo de 4cm de comprimento }\end{array}$ \\
\hline 20 & D3 & & Folha de papel entre as māos: rasgue a folha dobrada en quatro começando pela dobra \\
\hline 21 & D3 & & $\begin{array}{l}\text { Bola de tênis sobre a mesa: pegue a bola e depois vire a māo oompletamente para cima } \\
\text { segurando a bola }\end{array}$ \\
\hline 22 & D3 & & $\begin{array}{l}\text { Dedo no centro de um quadrado fixo: levante o dedo e depois o coloque sucessivarnente no centro } \\
\text { das oito casas do quadrado, sem tocar as linhrs }\end{array}$ \\
\hline 23 & D2 & & $\begin{array}{l}\text { Mernbros superiores ao lado do corpo: ao mesmo tempo coloque os dois antebraços e/ou as māos } \\
\text { sobre a mesa }\end{array}$ \\
\hline 24 & D1 & Sentado na cadeira & Levante-se, sem apoio dos membros superiores, om os pés próximos \\
\hline 25 & D1 & $\begin{array}{l}\text { Empé; apoio dos } \\
\text { membros superiores }\end{array}$ & Solte-se e mantenha-se en pé, com os pés próximos; cabeça, tronco e membros alinhados \\
\hline 26 & D1 & & Sem apoio dos membros superiores, levante um pé, por daz segundos \\
\hline 27 & D1 & Empé & Sem apoio, incline-se, toque o solo com uma das māos e depois se levante \\
\hline 28 & D1 & En pé sem apoio & Ande dez passos à frente, sobre ambos os calcanhares \\
\hline 29 & D1 & & Ande dez passos à frente, sobre uma linha reta \\
\hline 30 & D1 & & Corra dez metros \\
\hline 31 & D1 & & Salte no mesmo lugar, com um pé, dez vezes søguidas \\
\hline 32 & D1 & & Sem apoio dos membros superiores, agache-se e levante-se duas vezes em seguida \\
\hline
\end{tabular}

Fonte: adaptação/versão Bérard C, et al 
Anexo D - Escala de Vignos

\begin{tabular}{|c|c|}
\hline $\begin{array}{c}\text { Graduação } \\
0\end{array}$ & $\begin{array}{c}\text { Fases da Evolução } \\
\text { Pré-Clínico }\end{array}$ \\
\hline 1 & Anda normalmente, dificuldade para correr \\
\hline 2 & $\begin{array}{c}\text { Alteração detectável na postura ou marcha; sobe escada } \\
\text { sem auxílio do corrimão }\end{array}$ \\
\hline 3 & Apenas sobe escada com auxílio do corrimão \\
\hline 4 & Anda sem auxílio externo; não sobe escadas \\
\hline 5 & Anda sem auxílio externo; não levanta da cadeira \\
\hline 6 & Anda apenas com auxílio externo (uso de órteses) \\
\hline 7 & $\begin{array}{c}\text { Não anda; senta ereto na cadeira sem encosto; consegue } \\
\text { conduzir a cadeira de rodas; bebe e come sozinho }\end{array}$ \\
\hline 8 & $\begin{array}{c}\text { Senta sem suporte na cadeira; não consegue conduzir a } \\
\text { cadeira de rodas; não bebe sozinho }\end{array}$ \\
\hline 9 & $\begin{array}{c}\text { Não senta sem suporte na cadeira; não consegue beber ou } \\
\text { comer sem assistência }\end{array}$ \\
\hline 10 & Confinado à cama; requer auxílio para todas as atividades \\
\hline
\end{tabular}


ANEXO E - Manual de instrução -

Escala do levantar do solo (Manobra de Gowers)

\section{AVALIAÇÃO FUNCIONAL DE PORTADORES DE DMD NORMAS PARA PREENCHIMENTO}

O preenchimento das duas fichas relativas à avaliação da atividade de passar da postura de decúbito dorsal para bipedestação (FICHA 1) e de bipedestação para sedestação (FICHA 2) deve ser realizado concomitantemente com a observação do filme com o paciente realizando as mudanças de decúbito.

\section{FICHA 1}

Escala da manobra de Gowers para portadores de DMD

A manobra de Gowers é dividida em fases (mudanças posturais):

- De DD para flexão de tronco;

- De DD para DL;

- Assumir a postura sentada;

- Assumir a postura de gato ou ajoelhado;

- Posição de quadrupedia (posição de urso);

- Passagem do urso para bipedestação.

Durante a realização da avaliação o examinador pode fazer quantas observações achar necessário.

A tabela abaixo descreve as observações a serem realizadas em cada fase da manobra de Gowers que deve ser avaliada. O preenchimento deve ser realizado por meio de letras, cuja legenda segue abaixo.

\section{Legenda}
A $($ ) $=$ ausente.
$\mathbf{P}(\mathrm{)})$ presente.

Obs.: quando não aparecer $\mathrm{A}$ ou $\mathrm{P}$ na fase, significa que a atividade desta etapa tem que, necessariamente, estar presente.

\section{SENDO:}

DD = decúbito dorsal.

DL $=$ decúbito lateral.

MS $=$ membro superior .

MMSS $=$ membros superiores.

$\mathbf{4} \mathbf{p t}=$ quatro pontos.

$\mathbf{O U}$ - a fase que apresentar $\mathbf{O U}$ significa que tanto um quanto outro movimento pode ocorrer, se os dois movimentos estiverem presentes, anotar os dois. 


\section{- Fase de DD para flexão de tronco}

Observar se o paciente realiza a passagem de decúbito dorsal para flexão de tronco (como foi observado, alguns pacientes realizam pequena flexão de tronco antes de passar para DL). Se realizar sem apoio, (não registrar ponto), com apoio de um membro superior, (registrar um ponto) e com apoio dos membros superiores (registrar dois pontos). Se passar direto para sentado com apoio do MMSS, não registrar pontos. A compensação mais comum observada foi a rotação de tronco.

Registrar as compensações que o paciente realiza no espaço denominado enumerar compensações.

Anotar a pontuação no espaço denominado pontos de acordo com o movimento realizado, por exemplo, se o paciente passar de DD para flexão de tronco com apoio de um MS, você vai registrar 1 ponto.

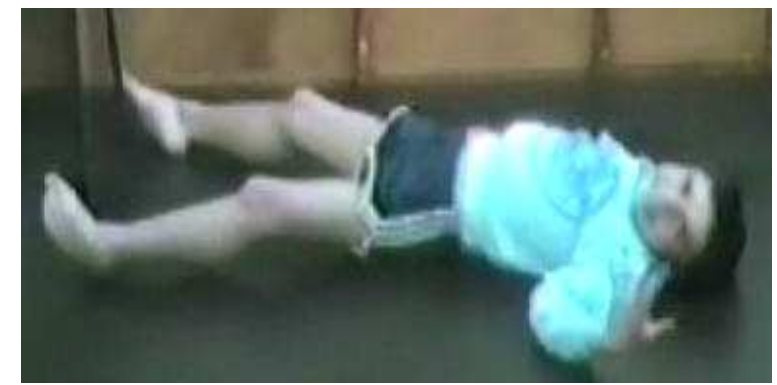

Figura 2. Posição de DD

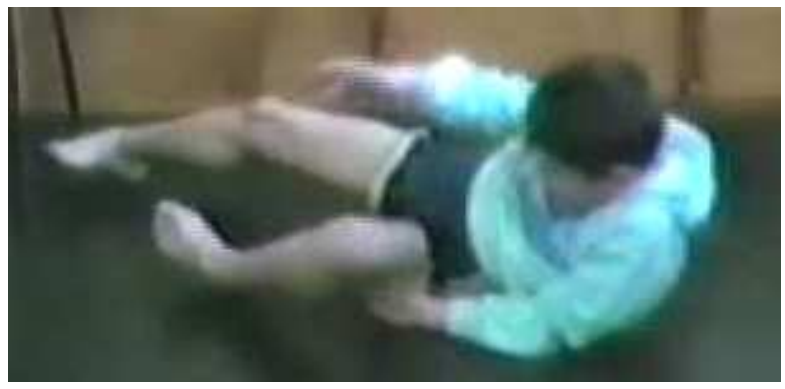

Figura 3. Passagem de DD para flexão de tronco

\section{- Fase de DD para DL}

Observar se o paciente realiza a passagem de decúbito dorsal para decúbito lateral. Se presente, registrar três pontos, se ausente não registre ponto. A compensação mais comum é a flexão de um ou dos dois membros inferiores.

Registrar as compensações que o paciente realiza no espaço denominado enumerar compensações.

Anotar a pontuação no espaço denominado pontos de acordo com o movimento realizado, por exemplo, se o paciente não passar de DD para flexão de tronco e sim para DL, você vai registrar 3 pontos.

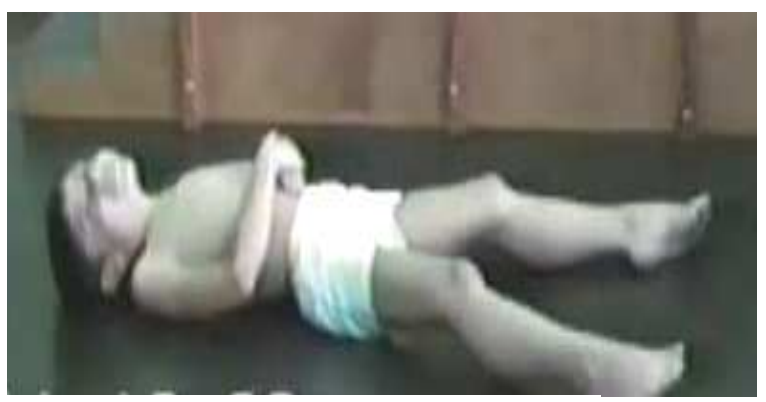

Figura 4. Posição de DD

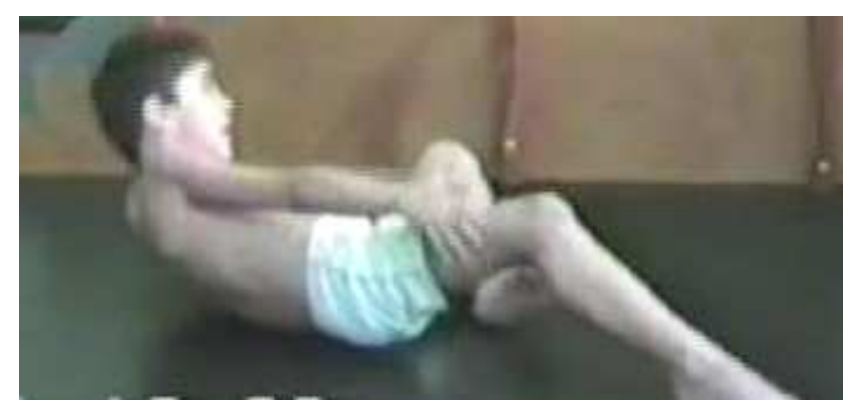

Figura 5. De DD para flexão de tronco. Observe que não realiza DL 


\section{- Assumir a postura sentada}

Observar se o paciente passa para sentado após flexão de tronco ou decúbito lateral. Se não, não registre ponto e passe para a próxima fase, se sim, anote e observe se ocorre estabilização sem apoio de membros superiores (um ponto), com apoio de um membro superior (dois pontos) e, com apoio de membros superiores (três pontos).

Anotar a pontuação no espaço denominado pontos de acordo com o movimento realizado, por exemplo, o paciente pode pular esta fase e ir direto para a posição de gato, então, não registrar ponto, se permanecer na posição sentada com apoio de um MS - você vai registrar 2 pontos.

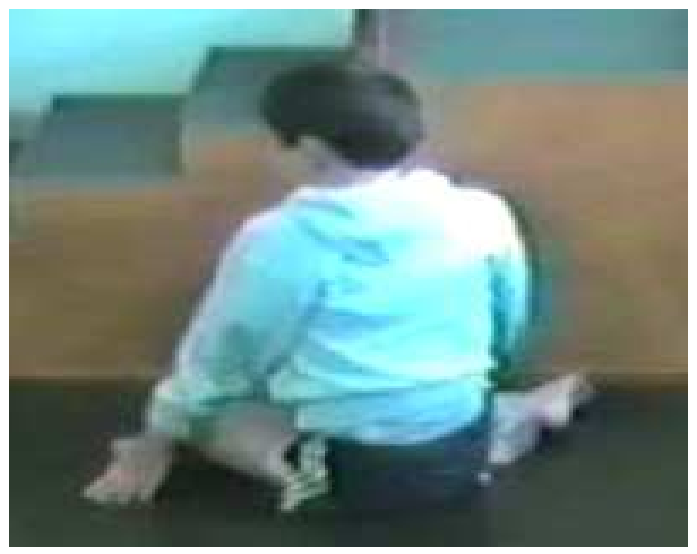

Figura 6. Passagem para a postura sentada

\section{- Assumir postura de gato ou ajoelhada}

Observar se o paciente passa para gato (apoio de pés, joelhos e MMSS no solo), não há pontuação, ou então, passa para ajoelhada (apoio de pés e joelhos no solo) e necessita de ponto de apoio externo, como cadeira, escada etc., permanecendo de joelhos, registre um ponto.

Anotar a pontuação no espaço denominado pontos de acordo com o movimento realizado, por exemplo, o paciente pode permanecer na posição de gato antes de se levantar, com isso não registrar pontos, se necessitar de apoio externo como uma cadeira, registrar 1 ponto.

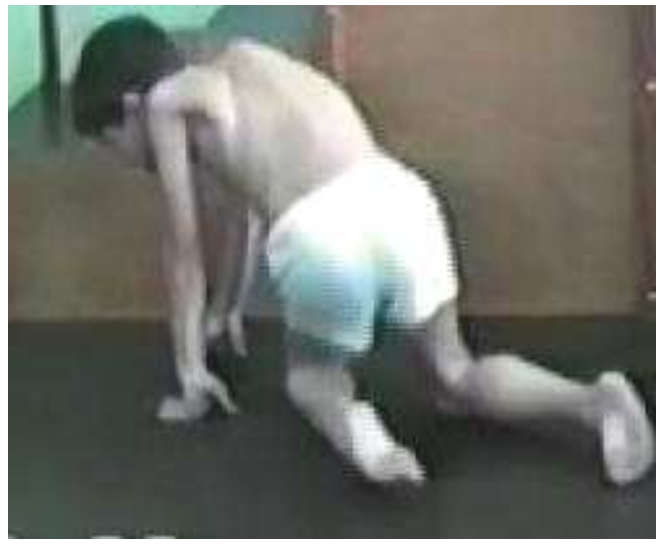

Figura 7. Passagem para gato

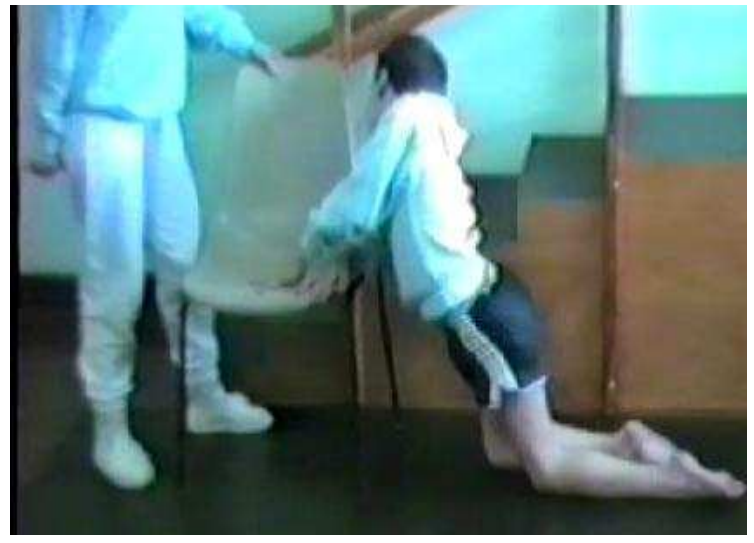

Figura 8. Ajoelhado com apoio externo 


\section{- Posição de quadrupedia}

Observar se o paciente realiza a posição de quadrupedia (apoio de pés e mãos no solo). Se não,

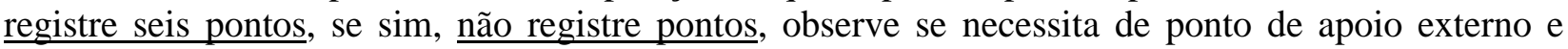
registre dois pontos.

Anotar a pontuação no espaço denominado pontos de acordo com o movimento realizado, por exemplo, após a posição de gato ele passa para quadrupedia com apoio de MMSS no solo, não registrar ponto.

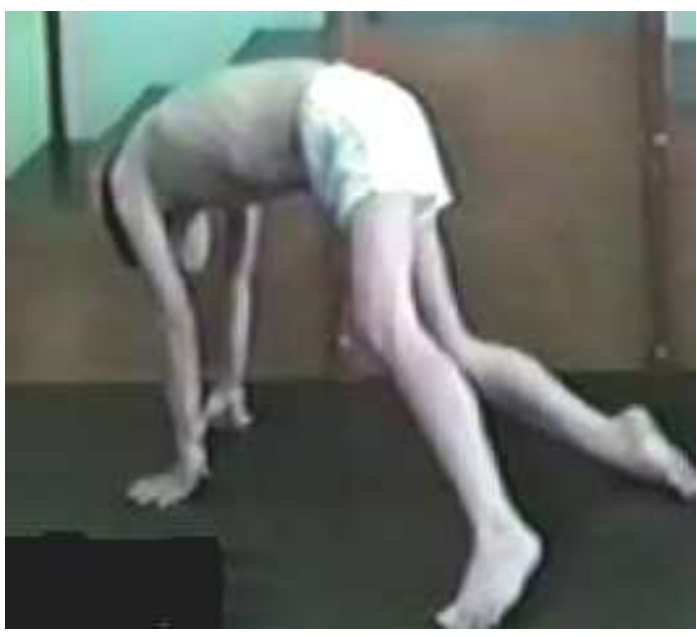

Figura 9. Posição de quadrupedia

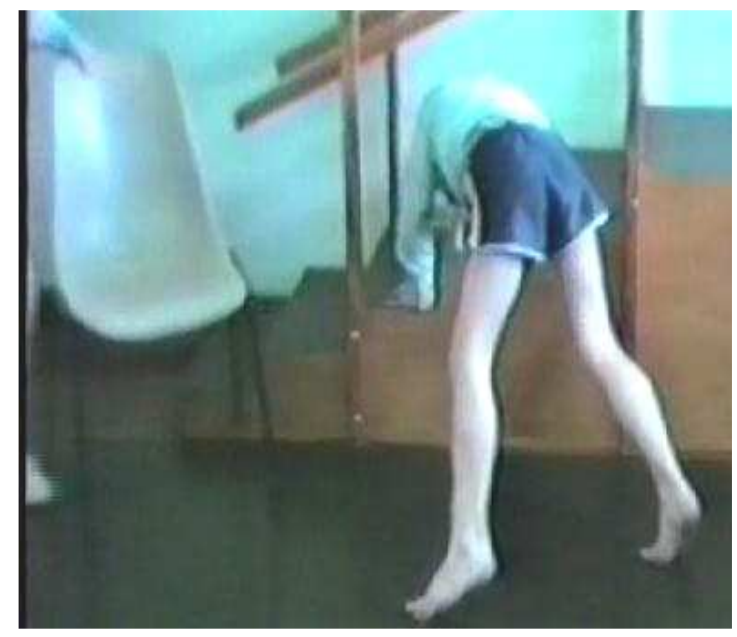

Figura 10. Quadrupedia com apoio externo

\section{- Passagem de quadrupedia para bipedestação}

Observe se o paciente realiza a passagem de quadrupedia para bipedestação escalando um membro superior no joelho (registre um ponto), se escala membros superiores em joelho e coxa (registre dois pontos), se escala membros superiores em perna, joelho e coxa (registre três pontos). Observe também se necessita de ponto de apoio externo, se sim, registre quatro pontos, se pára na posição de apoio externo e não realiza a manobra completa, registre cinco pontos.

Anotar a pontuação no espaço denominado pontos de acordo com o movimento realizado, por exemplo, para se levantar o paciente passa da posição de quadrupedia escalando (apoiando) MMSS em MMII.

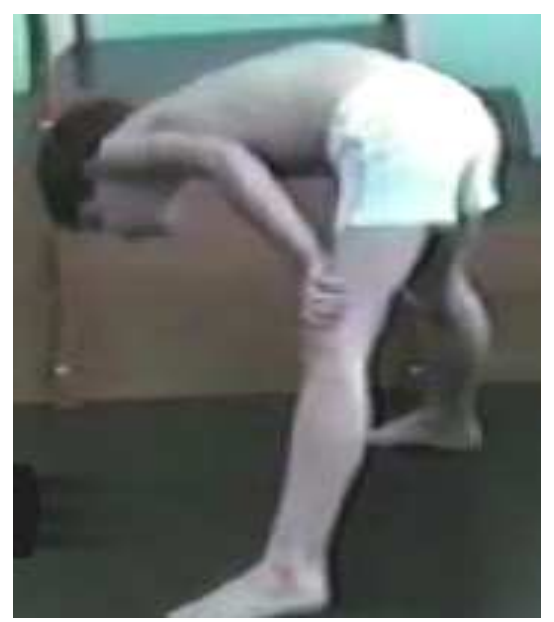

Figura 11. De quadrupedia para bipedestação escalando joelhos

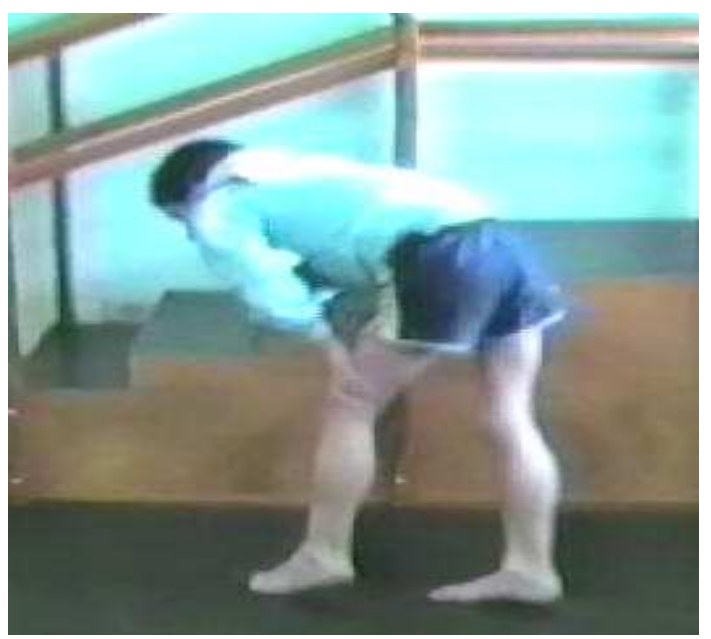

Figura 12. De quadrupedia para bipedestação escalando joelho e apoio externo 
Após analisar cada fase, REGISTRAR OS PONTOS E ANOTAR NA TABELA ABAIXO DA ESCALA. Quanto menor a nota, melhor o desempenho do paciente.

Começar a CRONOMETRAR o tempo a partir do decúbito dorsal até o final da manobra, onde é esperado que finalize em pé, se o paciente não completar a manobra, pare de cronometrar no momento em que conseguiu atingir seu máximo. 
ANEXO F - Manual de instrução - Escala do sentar no solo

\section{AVALIAÇÃO FUNCIONAL DE PORTADORES DE DMD NORMAS PARA PREENCHIMENTO}

O preenchimento das duas fichas relativas à atividade de passar da postura de decúbito dorsal para bipedestação (FICHA 1) e de bipedestação para sedestação (FICHA 2) deve ser realizado concomitantemente com a observação do filme com o paciente realizando as mudanças de decúbito.

\section{FICHA 2}

Escala da passagem de bipedestação para sedestação no solo

A passagem de bipedestação para sedestação no solo é dividida em fases:

1. Flexão de tronco com deslocamento do peso para frente;

2. Flexão de joelhos e tornozelos;

3. Posição sentada.

\section{Os registros seguem o mesmo formato proposto para FICHA 1.}

Descrição das fases envolvidas na passagem da postura de bipedestação para sedestação, a serem observadas e avaliadas:

- Flexão de tronco com deslocamento do peso para frente

Observar se o paciente realiza a flexão de tronco com deslocamento do peso para frente, sem apoio no solo (não registre ponto), com apoio de MMSS em MMII (registrar um ponto), com apoio de MMSS em MMII e em seguida no solo (registrar dois pontos), ou com apoio de MMSS diretamente no solo (registrar três pontos).

Anotar a pontuação no espaço denominado pontos de acordo com o movimento realizado, por exemplo, nesta passagem o paciente pode se jogar de encontro ao solo sem controle do tronco - você vai registrar 3 pontos.

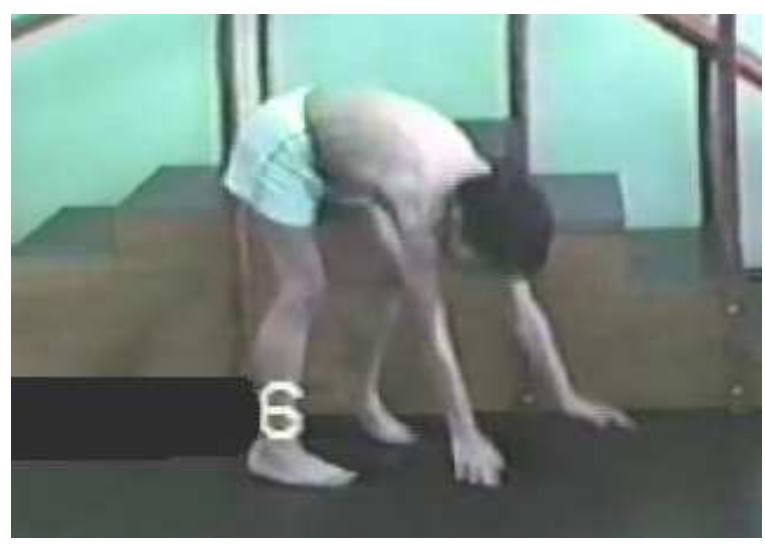

Figura 13. Flexão de tronco com deslocamento do peso para frente com apoio no solo 
- Flexão de joelhos e tornozelos

Observar o paciente no momento em que realiza flexão de joelhos e tornozelos (agachado), se realiza sem apoio (não registrar ponto) e se realiza com apoio de MMSS em MMII ou no solo (registrar dois pontos).

Anotar a pontuação no espaço denominado pontos de acordo com o movimento realizado, por exemplo, se o paciente agachar sem apoio não registrar ponto.

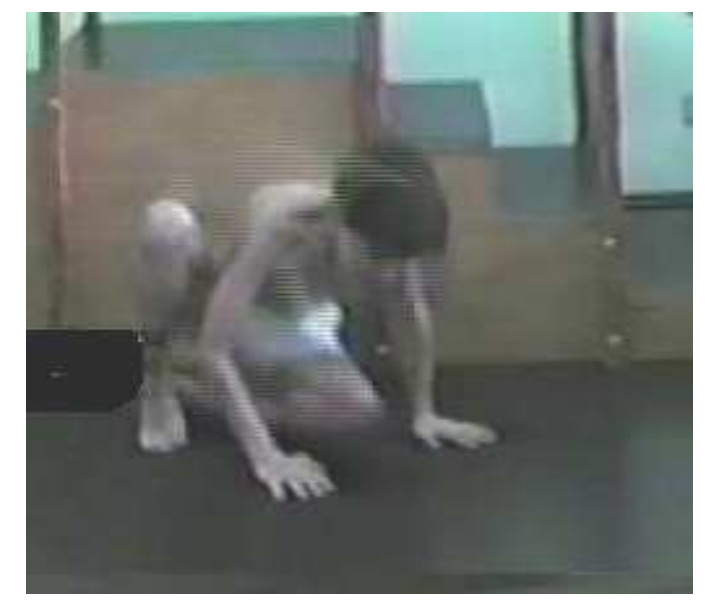

Figura 14. Agacha com apoio no solo

\section{- Posição sentada}

Observar o paciente no momento em que senta. Senta para trás (não registrar ponto), senta lateralizado (registrar um ponto), senta e estabiliza-se sem apoio de MMSS (não registrar ponto), senta e estabiliza-se com apoio de um membro superior (registrar um ponto), senta e estabiliza-se com apoio de membros superiores (registrar dois pontos) e observe também se o paciente simplesmente se joga (registrar três pontos).

Anotar a pontuação no espaço denominado pontos de acordo com o movimento realizado, por exemplo, nesta passagem o paciente pode simplesmente desabar e não sustentar o tronco para se estabilizar - você vai registrar 3 pontos.

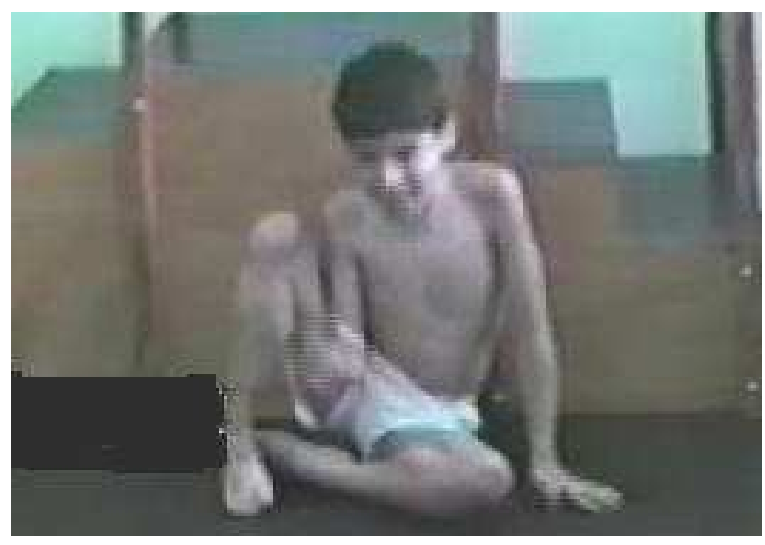

Figura 15. Senta lateralizado e se estabiliza com apoio de MS

Após analisar cada fase, REGISTRAR OS PONTOS E ANOTAR NA TABELA ABAIXO DA ESCALA. Quanto menor a nota, melhor o desempenho do paciente.

Começar a CRONOMETRAR o tempo a partir da postura de bipedestação até a postura de sedestação. Se o paciente não completar a manobra, pare de cronometrar no momento em que conseguiu atingir seu máximo. 


\section{REFERÊNCIAS}

1. Cyrulnik, S. E., Hinton, V. J. Duchenne muscular dystrophy: A cerebellar disorder? Neuroscience \& Biobehavioral Reviews. 2008; (32):486-496.

2. Uchikawa K, Liu M, Hanayama K, Tsuji T, Fujiwara T, Chino N. Functional status and muscle strength in people with Duchenne muscular dystrophy living in the community. J Rehabil Med. 2004; 36:124-9.

3. Kueh SLL, Head SI, Morley JW. GABA(A) receptor expression and inhibitory post-synaptic currents in cerebellar Purkinje cells in dystrophin-deficient mdx mice. Clin Exp Pharmacol Physiol. 2008; 35(2):207-10.

4. Mattar FL, Sobreira C. Hand weakness in Duchenne muscular dystrophy and its relation to physical disability. Neurmuscul Disord. 2008; 18: 193-8.

5. Palmieri, B. Sblendorio, V. Ferrari, A. Pietrobelli, A. Duchenne muscle activity evaluation and muscle function preservation: is it possible a prophylactic strategy? Obesity Reviews. 2008; (9):121-139.

6. Gozal D. Pulmonary manifestations of neuromuscular disease with special reference to DMD and spinal muscular atrophy. Pediatr Pulmonol.2000;29(2):141-8.

7. Bushby K. et al. The multidisciplinary management of Duchenne muscular dystrophy. Curr Pediatr. 2005; 15:292-300.

8. Wagner KR, Lechtzin N, Judge DP. Current treatment of adult DMD. Biochimica et Biophysica acta. 2007; 229-237.

9. Bérard C, Payan C, Hodgkinson I, Fermaniam J. A motor function measure scale for neuromuscular diseases. Construction and validation study. Neuromuscul Disord. 2005; 15:463-470. 
10. Steffensen BF, Lyager S, Werge B, Rahbek J, Mattsson E. Physical capacity in non-ambulatory people with Duchenne muscular dystrophy or spinal muscular atrophy: a longitudinal study. Developmental Medicine \& Child Neurology. 2002; 44: 623-632.

11. Mahoney FI, Barthel D. Functional evaluation: The Barthel Index. Maryland State Medical Journal. 1965; 14: 56-61.

12. Brooke MH, Griggs RC, Mendell JR. Clinical trial in DMD. The design of the protocol. Muscle \& Nerve. 1981; 4:186-197.

13. Vignos PJ, Spencer GE, Archibald KC. Management of Progressive Muscular Dystrophy os Childhood. JAMA. 1963; 2(184):103-10.

14. Scott E, Mawson SJ. Measurement in DMD: considerations in the development of a neuromuscular assessment tool. Dev Med Child Neurol. 2006; 48:540-4.

15. Alexander NB, Ulbrich J, Raheja A, Channer D. Rising from the floor in older adults. Journal of the American Geriatrics Socciety. 1997; 45:564-9.

16. Guarrera-Bowlby PL, Gentile Am. Form and variability during sit-to-stand transitions children versus adults. J Mot Behav. 2004; 36(1):104-14.

17. Araújo, CGS, Farinatti, PTV, Lira, VA. As ações de sentar e levantar do solo são influenciadas por variáveis morfo-funcionais. Rev. Paulista de Educação Física. $2002 ; 2: 230-41$.

18. Etnyre B, Thomas DQ. Event standardization of the sit-to-stand movements. Phys Ther. 2007; 87(12):1651-66.

19. Partridge, T. Pathophysiology of Muscular Dystrophy. British Journal of Hospital. Medicine. 1993; v. 49, n. 1. 
20. Essen van AJ, Busch HF, Meerman te GJ et al. Birth and population prevalence of Duchenne muscular dystrophy in The Netherlands. Human Genetics. 1992;88:258-266.

21. Rowland, L.P. Clinical Concepts of Duchenne Muscular Dystrophy. Brain, 1988.

22. Kanagawa M, Tatsushi T. The genetic and molecular basis of muscular dystrophy: roles of cell-matrix linkage in the pathogenesis. J Hum Genet. 2006; 51:915-926.

23. Monaco AP, Neve RL, Colletti-Feener C, Bertelson CJ, Kurnit DM, Kunkel LM. Isolation of candidate cDNAs for portions of the Duchenne muscular dystrophy gene. Nature. 1986;323:646-650.

24. Hoffman EP, Brown RH Jr, Kunkel LM. Dystrophin: the protein product of the Duchenne muscular dystrophy locus. Cell. 1987; 51:919-928.

25. Lapidos KA, Kakkar R, McNally EM. The dystrophin glycoprotein complex: signaling strength and integrity for the sarcolemma. Circ Res. 2004;94:1023-1031. 26. Deconinck N, Tinsley JM, Kahn D, et al. Expression of full length utrophin prevents muscular dystrophy in $m d x$ mice. Nat Med. 1998;14:1441-45.

27. Werneck, L.C. Perspectivas em Doenças Neuromusculares 1. Distrofia Muscular de Duchenne. Revista Brasileira de Neurologia. 1994; 30 (2): 33-35.

28. Kakulas, B.A.; Mastaglia, F.L. Pathogenesis and Therapy of Duchenne and Becker Muscular Dystrophy. New York; Raven Press; 1990.

29. Bohannon RW, Jones PL. Results of manual resistance exercise on a manifesting carrier of Duchenne muscular dystrophy. Phys Ther 1986; 66 (6): 973-5. 
30. Kudo, A.M. et. al. Fisioterapia, Fonoaudiologia e Terapia Ocupacional em Pediatria. Monografias Médicas, série Pediatria, v. 32 - São Paulo: Sarvier, 1994.

31. Mohamed K, Appleton R, Nicolaides P. Delayed diagnosis of Duchenne muscular dystrophy. Europ J Paediatr Neurol. 2000;4:219-223.

32. Crisp DE, Ziter FA, Bray PF. Diagnostic delay in Duchenne's muscular dystrophy. JAMA 1982;247:478-480.

33. Felisari G, Martinelli BF, Bardoni A et al. Loss of Dp140 dystrophin isoform and intellectual impairment in Duchenne dystrophy. Neurology. 2000;55:559-564.

34. Vinken, P.J.; Bruyn, G.W.; Klawans, H.L. X-linked Muscular Dystrophies. Handbook of Clinical Neurology, v. 62 - Myopathies, 1992.

35. Emery, A.E.H. Duchenne Muscular Dystrophy. Londres: Oxford Monographs on Medical Genetics, n. 24, 1994.

36. Cohen HJ, Molnar GE, Taft GE. The genetic relationship of progressive muscular dystrophy (Duchenne type) and mental retardation. Dev Med Child Neurol 1968;10:754-765.

37. Bresolin N, Castelli E, Comi GP et al. Cognitive impairment in Duchenne muscular dystrophy. Neuromuscul Disord 1994;4:359-369.

38. Essen van AJ, Verhij JBGM, Reefhuis $\mathbf{J}$ et al. The natural history of Duchenne muscular dystrophy. Analysis of data from Dutch survey and review of age related events. Thesis AJ van Essen 1997; Chapter 3;49-68:ISBN 903670711 0. 1997.

39. Nigro G, Comi LI, Politano L et al. The incidence and evolution of cardiomyopathy in Duchenne muscular dystrophy. Int J Cardiol 1990;26:271-277. 
40. Eagle M, Baudouin SV, Chandler C et al. Survival in Duchenne muscular dystrophy: improvements in life expectancy since 1967 and the impact of home nocturnal ventilation. Neuromuscul Disord. 2002;12:926-929.

41. Van Essen AJ, Kneppers AL, Van Der Hout AH, Scheffer H, Ginjaar IB, ten Kate LP, Van Ommen GJ, Buys CH, Bakker E. The clinical and molecular genetic approach to Duchenne and Becker Muscular Dystrophy: an updated protocol. J Med Genet. 1997; 34: 805-12.

42. Van Ommen GJ, Scheuerbrandt G. Neonatal screening for Muscular Dystrophy. Consensus recommendation of the 14th workshop sponsored by the European Neuromuscular Center (ENMC). Neuromuscul Disord. 1993; 3: 231-9.

43. Zatz M, Rapaport D, Vainzof M et al. Serum creatine-kinase (CK) and pyruvatekinase (PK) activities in Duchenne (DMD) as compared with Becker (BMD) muscular dystrophy. Neurol Sci. 1991;102:190-196.

44. Van Essen AJ, Busch HF, Meerman GJ, Kate LP. Birth and population prevalence of Duchenne Muscular Dystrophy in The Netherlands. Hum Genet. 1992; 88: 258-66.

45.Levy JA. Doenças musculares: estudo clínico e diagnóstico. Rio de Janeiro: Atheneu, 1989, 271p.

46. Griggs RC, Moxley III RT, Mendell JR, Fenichel GM, Brooke MH, Pestronk A, Miller JP. Prednisone in Duchenne dystrophy: a randomized, controlled trial defining the time course and dose response. Clinical Investigation of Duchenne Dystrophy Group, Arch. Neurol. 1991;48:383-388. 
47. Mendell JR, Moxley RT, Griggs RC et al. Randomized, doubleblind six-month trial of prednisone in Duchenne's muscular dystrophy, N. Engl. J. Med. 1989;320: $1592-1597$.

48. Manzur AY, Kuntzer T, Pike M, Swan A. Glucocorticoid corticosteroids for Duchenne muscular dystrophy (Review), Cochrane Library. 2006:1-41.

49. Moxley RT, Ashwal S, Pandya S et al. Practice parameter: corticosteroid treatment of Duchenne dystrophy. Report of the quality standards subcommittee of the American Academy of Neurology and the Practice Committee of the Child Neurology Society, Neurology. 2005; 64:13-20.

50. Pandya S, Guntrum D, Moxley RT. Long term daily prednisone therapy delays decline in pulmonary function and improves survival in patients with Duchenne dystrophy, Neuromuscul. Disord. 2005;15: 687.

51. Finder JD, Birnkrant D, Carl J et al. Respiratory care of the patient with Duchenne muscular dystrophy: ATS consensus statement, Am. J. Respir. Crit. Care Med. 2004;170.

52. Benditt JO, Boitano L. Respiratory support of individuals with Duchenne muscular dystrophy: toward a standard of care, Phys. Med. Rehabil. Clin. North Am. 2005;16:1125-1139.

53. Mohr CH, Hill NS. Long-term follow-up of nocturnal ventilatory assistance in patients with respiratory failure due to Duchenne-type muscular dystrophy, Chest. 1990; 97:91-96.

54. Simonds AK, Muntoni F, Heather S, Fielding S. Impact of nasal ventilation on survival in hypercapnic Duchenne muscular dystrophy, Thorax . 1998;53:949-952. 
55. Eagle M, Baudouin S, Chandler C. Giddings DR, Bullock R, Bushby K. Survival in Duchenne muscular dystrophy: improvements in life expectancy since 1967 and the impact of home nocturnal ventilation, Neuromuscul. Disord. 2002;12:926-929. 56. Vianello A, Bevilacqua M, Salvador V, Cardaioli C, Vincenti E. Longterm nasal intermittent positive pressure ventilation in advanced Duchenne muscular dystrophy, Chest. 1994;105:445-448.

57. Caromano FA, Kuga LS, Passarella J, Sá CSC. Efeitos fisiológicos de sessão de hidroterapia em crianças portadoras de distrofia muscular de duchenne. Rev Fisioter Univ São Paulo. 1998; 5 (1): 49-54.

58. Nair KP, Vasanth A, Gourie-Devi M, Taly AB; Rao S, Gayathri N et al. Disabilities in children with Duchenne muscular dystrophy: a profile. J Rehabil Med. 2001;33:147-9.

59. Escorcio, R et al. Caracterização da passagem de bipedestação para sedestação no solo e da passagem de decúbito dorsal no solo para bipedestação em crianças normais. Revista de Terapia Ocupacional da Universidade de São Paulo. 2007;18:44-6.

60. Araújo, PTV, Lira, V. Teste de sentar-levantar: estudos de fidedignidade. Revista Brasileira Ciência e Movimento. 2000; 8:09-18.

61. Van Den Beld, WA et al. A new motor performance test in a prospective study on children with suspected myopathy. Developmental Medicine\& Child Neurology. 2006; 48: 739-43.

62. Kang PB, Krishnamoorthy KS, Jones RM, Shapiro FD, Darras BT. Atypical presentations of spinal muscular atrophy type III (Kugelberg-Welander disease). Neuromuscul Disord. 2006; 16:492-4. 
63. Fehring RJ. Validation diagnostic labels: standardized methodology. In: Hurley ME. Classification of nursing diagnoses: procedings of the sixt Conference of North American Nursing Association. St. Louis: The C.V. Morby. 1986: 183-90.

64. Iunes $\mathrm{DH}$ et al. Confiabilidade intra e interexaminadores e repetibilidade da avaliação postural pela fotogrametria. Revista Brasileira de Fisioterapia. 2005; 9 (3): 327-34.

65. Carr JH et al. Investigation of a new motor assessment scale for stroke patients. Phys Ther. 1985; 65 (2):175-80.

66. Weir, JP. Quantifying test-retest reliability using the intraclass correlation coefficient and the SEM. Journal of Strength and Conditioning Research. 2005; 19(1): 231-40.

67. Wahlund K, List T, Dworkin. Temporomandibular disorders in children and adolescents: reliability of a questionnaire, clinical examination, and diagnosis. Journal of Orofacial Pain (Carol Stream). 1998; 12 (1): 42-51.

68. Landis JR, Koch GG. The measurement of observer agreement for categorical data. Biometrics. 1977; 33: 159-75.

69. Bakker JPJ, Groot IJM, Beelen A, Lankhorst GJ. Predictive factors of cessation of ambulation in patients with duchenne muscular dystrophy. Am J Phys Med Rehabil. 2002; 81:906-12.

70. Ansved T. Muscular dystrophies: influence of physical conditioning on the disease evolution. Current Opinion in Clinical Nutrition and Metabolic Care. 2003; $6: 435-39$.

71. Grange RW, Call J A. Recommendations to Define Exercise Prescription for Duchenne Muscular Dystrophy. Exercise and Sport Sciences Reviews. 2003; 6:43539. 


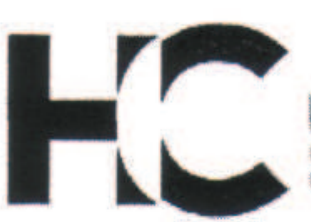

Ao

Departamento de Fisioterapia/Fonoaudiologia e Terapia Ocupacional

O Presidente da Comissão de Ética para Análise de Projetos de Pesquisa - CAPPesq da Diretoria Clínica do Hospital das Clínicas e da Faculdade de Medicina da Universidade de São Paulo, em 11.09.06, tomou conhecimento que o Protocolo de Pesquisa $n^{\circ} 837 / 05$ intitulado: "Elaboração, validação e aplicação de escala de avaliação funcional para portadores de distrofia muscular de Duchenne (DMD)", aprovado por esta Comissão em 24.11.05, contempla o subprojeto intitulado: "Elaboração e validação de escala de avaliação funcional da manobra de Gowers e da manobra de passagem de bipedestação para sedestação no chão para portadores de distrofia muscular de Duchenne (DMD)", que será dissertação de mestrado da SRA. RENATA ESCORCIO, tendo como orientadora PROFA. DRA. FÁTIMA APARECIDA CAROMANO.

\footnotetext{
buld Geflo

PROF. DR. EUCLIDES AYRES DE CASTILHO Presidente da Comissão de Ética para Análise

Dimil P. Manzues de Projetos de Pesquisa

Prof.9 Dra. Amélia Pasqual Marques Coordenádora do Programa de Pós-Graduaçáo em Ciencias da Reabilitaçăo-FMUSP
} 


\section{UNIVERSIDADE DE SÃO PAULO}

\section{AUTORIZAÇÃO}

Autorizo pela presente, a Profa. Fatima Caromano, a utilizar as fitas de vídeo com informações de portadores de Distrofia Muscular, somente para estudo da evolução clínica dos pacientes.

São Paulo, 7 de Junho de 2004

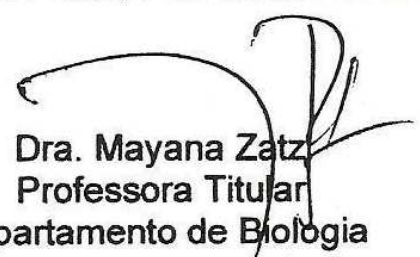

Coordenadora do Centro de Estudos do Genoma Humano

Instituto de Biociências - USP 